\title{
COVID-19: Imbalanced Immune Responses and Potential Immunotherapies
}

\author{
Bing Xie ${ }^{1 \dagger}$, Jiancheng Zhang ${ }^{1 \dagger}$, Yuwen $\mathrm{Li}^{2}$, Shiying Yuan ${ }^{1 *}$ and You Shang ${ }^{1 *}$ \\ ${ }^{1}$ Department of Critical Care Medicine, Union Hospital, Tongji Medical College, Huazhong University of Science and \\ Technology, Wuhan, China, ${ }^{2}$ Hayward Genetics Center, Tulane University School of Medicine, New Orleans, LA, United States
}

\section{OPEN ACCESS}

Edited by:

Ruchi Tiwari,

U.P. Pandit Deen Dayal Upadhyaya Veterinary University, India

Reviewed by:

Namir Shaabani,

The Scripps Research Institute,

United States

Anass Bouchnita,

Casablanca Central School, Morocco

*Correspondence:

You Shang

you_shanghust@163.com

Shiying Yuan

yuan_shiying@163.com

${ }^{\dagger}$ These authors have contributed equally to this work

Specialty section:

This article was submitted to Viral Immunology,

a section of the journal

Frontiers in Immunology

Received: 17 September 2020

Accepted: 23 December 2020

Published: 29 January 2021

Citation:

Xie B, Zhang J, Li Y, Yuan S and Shang Y (2021) COVID-19: Imbalanced Immune Responses and

Potential Immunotherapies.

Front. Immunol. 11:607583. doi: 10.3389/fimmu.2020.607583
The ongoing pandemic coronavirus disease 2019 (COVID-19) caused by severe acute respiratory syndrome coronavirus 2 (SARS-CoV-2) is rapidly spreading and has resulted in grievous morbidity and mortality worldwide. Despite the high infectiousness of SARSCoV-2, the majority of infected individuals are asymptomatic or have mild symptoms and could eventually recover as a result of their balanced immune function. On the contrary, immuno-compromised patients are prone to progress into severe or critical types underpinned by the entanglement of an overexuberant proinflammatory response and injured immune function. Therefore, well-coordinated innate and adaptive immune systems are pivotal to viral eradication and tissue repair. An in-depth understanding of the immunological processes underlying COVID-19 could facilitate rapidly identifying and choosing optimal immunotherapy for patients with severe SARS-CoV-2 infection. In this review, based on current immunological evidence, we describe potential immune mechanisms and discuss promising immunotherapies for COVID-19, including IL-6R blockades, convalescent plasma, intravenous gamma globulin, thymosin alpha1, corticosteroids, and type-I interferon, and recent advances in the development of COVID-19 vaccines.

Keywords: coronavirus disease 2019, severe acute respiratory syndrome coronavirus 2, pathogenesis, immunomodulation, IL-6R blockade, convalescent plasma, intravenous gamma globulin, thymosin alpha1

\section{INTRODUCTION}

The ongoing coronavirus disease 2019 (COVID-19) pandemic triggered by severe acute respiratory syndrome coronavirus 2 (SARS-CoV-2) has gripped the world in an unprecedented crisis, entailing issues with the economy, health care, and education. Millions of people worldwide have suffered from this highly contagious disease. The vast majority of infected patients had a good prognosis, but there were still some severe and critical cases and even deaths (1). Epidemiological studies show that the progression of pulmonary infiltrates and multiorgan failure was commonly concomitant with markedly elevated serum proinflammatory cytokines (i.e., interleukin (IL)-2R, IL-6, IL-10, IL-8, and tumor necrosis factor (TNF- $\alpha)$ ) and other biomarkers of inflammation (i.e., procalcitonin, Creactive protein (CRP), and ferritin) (2-4). Besides this, protracted and severe lymphopenia strongly correlates with adverse outcomes and fatality $(4,5)$. Together, these clinical observations indicate that, apart from direct viral toxicity, immune dysregulation serves as an independent and potent 
contributor to disease aggravation. Thus, a better understanding of the immunological mechanisms underlying the physiopathology in SARS-CoV-2-infected patients is necessary for identifying therapeutic targets and appropriate deployment of therapies. Large amounts of research have been conducted to evaluate immune-related therapies for COVID-19 in clinical applications or trials; however, a consensus on a specific therapeutic strategy has not yet been reached. In this review, we discuss the role of immune responses in the development of COVID-19 and summarize current clinical results of several promising immunomodulatory agents and vaccines for COVID19 (Table 1).

\section{COVID-19: SARS-CoV-2 Intrusion and Innate Immune Hyperactivation}

SARS-CoV-2 is a large, enveloped, positive-sense, singlestranded RNA virus belonging to beta coronaviruses and shares $82 \%$ homology with the genomic sequence of SARS$\mathrm{CoV}$ (6). The SARS-CoV-2 RNA genome covers approximately 30 kilobases and encodes four main structural proteins (the spike $(\mathrm{S})$, envelope $(\mathrm{E})$, membrane $(\mathrm{M})$, and nucelocapsid $(\mathrm{N})$ protein), 16 nonstructural proteins (Nsp1-16) and 7 accessory proteins (ORF3a, 3b, 6, 7a, 7b, 8, 9b, 9c, and 10) (7). Structural and nonstructural proteins synergistically sustain viral survival and infectious power, and accessory proteins regulate host responses to promote infection and pathogenesis. SARS-CoV-2 uses angiotensin-converting enzyme 2 (ACE2) as a portal for viral entry (8). ACE2 is ubiquitously expressed in almost all organs in human, among which type- 2 alveolar cells possess an abundance of ACE2 (9), partially contributing to the commonly observed acute respiratory distress syndrome (ARDS) in critical COVID19 cases. There is literature suggesting CD147 as a receptor for SARS-CoV-2 invasion (10); however, to what extent this pathway contributes to viral entry and replication requires further elucidation. Viral infection and replication in airway epithelial cells cause the damage to infected lung cells and vascular leakage as well as the release of inflammatory mediators (11). The released virus-associated damageassociated molecular patterns (DAMPs), involving intracellular contents from dying cells (12) as well as pathogen-associated molecular patterns (PAMPs), including viral RNA (13), are identified by multiple pattern-recognition receptors (PRRs) on innate immune cells, such as dendritic cells, monocytes, macrophages, neutrophils, and epithelial cells (14). Endosomal RNA PRRs involve toll-like receptors (TLR-)3 and 7, and cytosolic sensors include retinoic acid-inducible gene 1 (RIG-I) and melanoma differentiation-associated gene 5 (MDA5) (15). After the recognition of virus invasion, a series of intracellular inflammatory signaling pathways are then activated, and inflammatory products are then generated and secreted, among which, type-I IFN (IFN-I) is considered to play a central role in the first-line antiviral defense. Upon recognizing RNA ligands, the caspase activation and recruitment domain (CARD) is exposed and activates the mitochondrial antiviral adaptor protein (MAVS) to start downstream signaling. IFN regulatory factor (IRF) 3 and 7 then undergo phosphorylation and translocate to the nucleus, inducing the expression of IFN-I genes and interferon-stimulated genes (ISGs) $(16,17)$. Moreover, TLR-3/7 activation leads to nuclear translocation of the NFKB and IRF3 (15). These transcription factors induce the expression

TABLE 1 | COVID-19: imbalanced immune responses and promising immunotherapies.

\begin{tabular}{|c|c|c|c|}
\hline Intervention & Published data in COVID-19 as of July 19, 2020 & $\begin{array}{l}\text { Mechanism } \\
\text { of action }\end{array}$ & Recommendations \\
\hline $\begin{array}{l}\text { IL-6R } \\
\text { blockades: } \\
\text { Tocilizumab } \\
\text { Sarilumab }\end{array}$ & $\begin{array}{l}\text { Observational studies with inconsistent results: Case } \\
\text { series and retrospective cohort studies reported } \\
\text { improved outcomes; one case report found no beneficial } \\
\text { therapeutic effect }\end{array}$ & $\begin{array}{l}\text { Monoclonal } \\
\text { antibody against } \\
\text { IL-6 }\end{array}$ & $\begin{array}{l}\text { Prudent use of IL-6 targeting therapies with antiviral agents in cases } \\
\text { with early, rapid, continuous deterioration and clinical and laboratory } \\
\text { proof of overactive inflammatory responses (i.e., rapidly aggravating } \\
\text { state of breathing, shock, and elevations in IL-6 and CRP) }\end{array}$ \\
\hline $\begin{array}{l}\text { Convalescent } \\
\text { plasma }\end{array}$ & $\begin{array}{l}\text { Observational studies reported improvements in clinical } \\
\text { outcomes; one randomized clinical trial with hopeful but } \\
\text { not statistically significant results }\end{array}$ & $\begin{array}{l}\text { Provides } \\
\text { protective } \\
\text { antibody against } \\
\text { SARS-CoV-2 }\end{array}$ & $\begin{array}{l}\text { Application in patients displaying advanced disease course with severe } \\
\text { viremia }\end{array}$ \\
\hline IVIG & $\begin{array}{l}\text { Observational studies report clinical improvements as an } \\
\text { adjuvant agent }\end{array}$ & $\begin{array}{l}\text { Provides passive } \\
\text { immunity and anti- } \\
\text { inflammatory } \\
\text { effects }\end{array}$ & Application in COVID-19 as an adjuvant agent \\
\hline $\begin{array}{l}\text { Thymosin } \\
\text { alpha1 }\end{array}$ & $\begin{array}{l}\text { Observational studies report therapeutic benefit in } \\
\text { recovery of } \mathrm{T} \text { cell numbers. }\end{array}$ & $\begin{array}{l}\text { Polypeptide with } \\
\text { immunoregulatory } \\
\text { effects }\end{array}$ & $\begin{array}{l}\text { Application as an adjuvant agent in COVID-19 cases, especially with } \\
\text { lymphopenia }\end{array}$ \\
\hline Corticosteroids & $\begin{array}{l}\text { Observational studies found possible clinical benefit in } \\
\text { ARDS, but there remains concern about prolonged virus } \\
\text { shedding and hazard of high dosing; the recovery trial } \\
\text { reports improvement in clinical outcomes }\end{array}$ & $\begin{array}{l}\text { Inhibit } \\
\text { inflammatory cells } \\
\text { and dampen } \\
\text { proinflammatory } \\
\text { cytokines }\end{array}$ & $\begin{array}{l}\text { Short-term and low-dose application in patients with respiratory } \\
\text { disorders, simultaneously with close monitoring }\end{array}$ \\
\hline IFNs & $\begin{array}{l}\text { Type-I IFNs combined with other antiviral agents } \\
\text { demonstrate clinical efficacy in one observational study }\end{array}$ & $\begin{array}{l}\text { Suppress virus } \\
\text { replication }\end{array}$ & $\begin{array}{l}\text { Early administration with other antiviral agents preceding the peak of } \\
\text { viremia or prophylactic treatment might confer protection }\end{array}$ \\
\hline
\end{tabular}

ARDS, acute respiratory distress syndrome; COVID-19, corona virus disease 2019; IFNs, interferons; IL-6R, interleukin 6 receptor; IVIG, intravenous gammaglobulin; SARS-CoV-2, severe acute respiratory syndrome coronavirus 2. 
of genes that encode cytokines (IL-1, IL-6, TNF- $\alpha$, etc.) and chemokines (CXCL10, CXCL8, CXCL9, CCL2, etc.). The increase of multiple inflammatory cytokines and chemokines attracts a variety of innate immune cells as well as adaptive cells to the inflamed site for virus control (18).

Early sufficient production of IFN-I is paramount to the control of viral dissemination and effective viral clearance. However, low circulating levels of IFNs are regularly detected in severe COVID-19 patients (19) and seemingly related to illness severity (20). Notably, the contrasting observations of robust IFN responses, hallmarked by highly expressed ISGs, were detected in the bronchoalveolar lavage fluid (BALF) of some critically ill patients (21). Also, the succumbed patients displayed significantly elevated levels of plasma IFN- $\alpha$ and IFN- $\lambda$ throughout the disease course, and these were highly correlated with viral load (22). The discrepancy of IFN dynamics between the inflamed lung and the circulatory system of severe and critical COVID-19 patients may reflect an incapability of viral control in very early stages of viral invasion, contributing to systemic compromised antiviral responses (low circulating IFN levels) or uncontrolled harmful IFN responses. Furthermore, the strong IFN responses in the lungs fail to restrain disease progression through suppressing viral replication, suggesting that SARS-CoV-2 might have evolved mechanisms to evade innate immune killing. Given the high homogeneity between SARS-CoV-2 and SARS-CoV, there are good theoretical reasons to believe that SARS-CoV-2 might exploit similar mechanisms to inhibit IFN-I response. SARS-CoV ORF3b is reported to interfere with IRF3 or MAVS to inhibit IFN induction (17). SARS-CoV is also found to inhibit the TNF receptor-associated factors (TRAF) 3 and 6, which are essential for the induction of IRF3/7 (23). Furthermore, it is reported that ORF9b of SARSCoV-2 could inhibit MAVS activation, which is required for nuclear translocation of IRF3 (17). Importantly, SARS-CoV-2 Nsp1 is shown to bind to human $40 \mathrm{~S}$ ribosomal subunits, thus blocking host mRNA translation involving that of IFN-I (24).

IL-6 is a prompt effector in response to acute infections, and it can be produced by extensive cells, including fibroblasts; endothelium cells; and immune cells, such as macrophages, monocytes, B lymphocytes, and T lymphocytes (25). Hyperactivated IL-6 might promote inflammation cascades. IL6 functions partly through trans signaling via binding to soluble bound IL-6 receptor (sIL-6R), which is expressed by virtually all body cells (including stromal and epithelial cells) (26). The binding of IL-6 and widely expressed sIL-6R is likely to fuel the hyperinflammation and be partially responsible for severe ARDS and multiorgan failure in COVID-19. It is reported that IL-6 could serve as a predictive marker for the severity of COVID-19 (27). Evidence has shown that IL-6 levels in COVID-19 patients needing critical care continues to increase over time and are relatively more elevated in nonsurvivors than in survivors (28). However, circulating concentration of IL-6 and other inflammatory cytokines (e.g., IL-8, TNF- $\alpha$, IFN- $\gamma$ ) in patients with severe and critical COVID-19 is far from the median levels of that in cytokine release syndrome, sepsis, and ARDS unrelated to COVID-19 (29). As such, the role of a cytokine storm wherein IL-6 is considered to be highly involved in the pathogenesis of COVID-19 warrants further exploration.

Abundant activated dendritic cells, activated mast cells, and neutrophils along with a significant neutrophil-to-lymphocyte (NLR) ratio were observed in the BALF of COVID-19 patients (21), which is supported by a study showing higher NLR in severe COVID-19 cases (30). Increased plasma levels of neutrophils and eosinophils were correlated with the severity of COVID-19 (22). In another single-cell RNA sequencing (scRNA-seq) analysis, severe COVID-19 patients with ARDS showed a pronounced increase of peripheral activated granulocytes. Altogether, these data indicate the pathogenic role of granulocytes in the development of COVID-19. In parallel, the dysregulation of monocytes and macrophages seems to be a driving contributor in the pathogenesis of severe SARS-CoV-2 infection although conflicting results exist. CCL2 and CCL7, as two potent chemokines for recruiting CCchemokine receptor 2-positive $\left(\mathrm{CCR} 2^{+}\right)$monocytes, were found in the BALF of severely infected COVID-19 patients (31). In addition, evidence indicates an activated phenotype of monocytes involved in the immunologic pathogenesis of COVID-19. Zhou et al. report a significantly higher proportion of inflammatory monocytes with a high expression of IL- 6 and granulocyte-macrophage colony-stimulating factor (GM-CSF) in the peripheral blood of COVID-19 patients (32). Even in the recovery stage of COVID-19, Wen et al. observed a greater abundance of circulating CD $14^{+} \mathrm{IL}-1 \beta^{+}$and IFN-activated monocytes in infected patients in comparison with healthy controls (33). Although Wilk et al. did not observe substantial expression of proinflammatory cytokine genes on circulating monocytes in COVID-19, they did identify severe cases of COVID-19 showing a depletion of $\mathrm{CD}^{+} 6^{+}$monocytes and a prominent shift toward CD14 $4^{+}$monocytes (34). Macrophages are often derived from circulating monocytes and actively implicated in the pathogenesis of a cytokine storm. Activated macrophages could secret an excessive amount of inflammatory cytokines, including IL-1, IL-6, IL-18, and MCP-1 (35). ScRNAseq analysis reveals an accumulation of classic M1-like and alternative M2-like inflammatory macrophages in patients with severe COVID-19 (36). Compared to the moderate type of COVID-19 patients and healthy controls, macrophages in the lungs of severe cases are more prone to express inflammatory cytokines and chemokines, indicative of a contribution to the local inflammatory environment. Moreover, the M2-like subset is related to tissue repair and fibrosis as well as suppression of antiviral effector $\mathrm{T}$ cell responses, eliciting concerns about fibrotic complications and immunodeficiency in COVID-19, respectively. Notably, autopsy reports show that secondary lymphoid tissue-resident $\mathrm{CD} 8^{+}$and $\mathrm{CD} 169^{+}$macrophages of COVID-19 patients expressed ACE2 and contained the SARSCoV-2 nucleoprotein (31). In addition, SARS-CoV-2-infected macrophages are triggered to secrete IL-6. Collectively, these findings provide evidence about the pathological role of inappropriate macrophage responses in SARS-CoV-2 infection. Studies show depleted peripheral NK cells in severe cases of 
COVID-19 in comparison with that in mild cases and healthy controls $(33,34,37)$. Furthermore, an exhausted phenotype of peripheral NK cells with a high expression of NKG2A was observed in COVID-19 patients. Notably, scRNA-seq analysis shows that BALF samples in patients with various severities of COVID-19 had a higher percentage of NK cells than those in healthy people (36), which raises the possibility of the trafficking of peripheral NK cells to inflamed lungs. The scanty functional NK cells and exuberant inflammatory monocytes in the peripheral blood may fuel the dissemination of SARS-CoV-2 and the successive serious injury of extrapulmonary organs.

\section{COVID-19: Adaptive Immune Dysregulation}

The activation of the innate immune system and the resultant secretion of proinflammatory cytokines and chemokines subsequently recruit a variety of adaptive immune cells to the inflamed site to prime corresponding adaptive immune responses, including $\mathrm{CD}^{+}$effector $\mathrm{T}$ cell-mediated cytotoxicity, $\mathrm{CD}^{+} \mathrm{T}$ cell-dependent cytokine release, and $\mathrm{B}$ cell activation-dependent antibody production. Orchestrated innate and adaptive immune responses are capable of clearing the novel coronavirus. In parallel, inflammatory cytokines generated by innate and adaptive immune cells steadily decline (22). Nonetheless, COVID-19 patients with disease progression present with abnormal immune profiles, including sustained high levels of circulating proinflammatory factors (IL-6, IL-1 $\beta$, IL-2, IL-8, IL-17, IL-18, IL-22, G-CSF, GM-CSF, IP10, MCP1, MIP1 $\alpha$, and TNF- $\alpha$, etc.) $(22,38-41)$, known as a "cytokine storm," as well as lymphopenia (involving reduced numbers of $\mathrm{CD}^{+} \mathrm{T}$ cells, $\mathrm{CD}^{+} \mathrm{T}$ cells, and NK cells) $(22,40)$ with the remaining $\mathrm{T}$ and NK cells tending to exhibit reduced functional diversity and a more exhausted phenotype $(34,42,43)$. As mentioned, SARS-CoV-2 has exploited various strategies to achieve immune evasion. The persistent infection state leads to prolonged immune activation of both the innate and adaptive immune systems. Innate and adaptive immune cells secret large amounts of immune-active molecules to recruit and activate each other (35). With the lack of an efficient negative feedback system, immune cells in severe COVID-19 exert cascade-amplification effects, which lead to collateral tissue damage in the lung and other organs, resulting in cardiovascular, gastrointestinal, renal, and hepatic injuries (44). The cytokine storm is recognized to be a critical pathogenic contributor to the development of ARDS (45). The influx of various immune cells and accumulation of inflammatory mediators damage the alveolus-capillary membrane with consequent fluid accumulation in the lungs leading to difficulty of gas exchange. Moreover, the severe disease course could finally progress into multiple organ dysfunction syndromes, which have been observed in severely infected patients with COVID-19 (46). Furthermore, critical COVID-19 patients are prone to develop coagulation disorders as it is reported that a $31 \%$ incidence of thrombotic complications occur in COVID patients admitted to the ICU, including acute pulmonary embolism (PE), deep-vein thrombosis (DVT), and so on (47). The observed hemostatic disorders could be attributed to hyperinflammation-induced endothelial dysfunction (48). In addition, autoimmunity against phospholipids in COVID-19 may be contributory to the development of abnormal coagulation. Half of in-hospital COVID-19 patients had at least one type of serum antiphospholipid antibodies when eight types of antiphospholipid antibodies were measured (49). The autoantibodies to phospholipids not only predispose the endothelium into a prothrombotic state, but they trigger the release of neutrophil extracellular traps (NETs) from neutrophils, which further exacerbates thrombus formation through several mechanisms. Of note, the potently increased serum levels of CXCL9 (chemoattractants of T cells), CXCL16 (chemoattractant of NK cells), C-C motif chemokine 8 (CCL8), CCL2 (recruiting monocytes and/or macrophages), and CXCL8 (majorly attracting neutrophils) were observed in patients infected with SARS-CoV-2 compared with noninfected individuals $(19,22)$, suggesting a potential contribution of these immune cells in hypercytokinemia.

As mentioned, lymphopenia is a salient feature of SARS$\mathrm{CoV}-2$ infection. Besides the unproven direct virus-induced lymphocyte disruption and sequestration in the lung lesion (41), lymphocyte apoptosis induced by inflammatory cytokines, such as IL- 6 and TNF- $\alpha$, may also play a pivotal role (50). Notably, evidence shows a dysregulated profile of the adaptive immune system in the severe disease course with relatively high humoral immune and low cellular immune responses, supported by increased amounts of circulating total and effector B cells as well as reduced T effector cells (20,51). As part of the humoral immune response to SARS-CoV-2, virusspecific IgM and IgG were detected on days 7 and 10 after illness onset, respectively. Severe COVID-19 cases are prone to display earlier and higher titers of IgM and IgG, indicative of a potential correlation of strong antibody response with disease severity (52). Of note, a recent study reveals a specific IgG Fc structure characterized by reduced fucosylation in adult COVID-19 patients (53). The modified Fc structure confers IgG 5- to 10fold higher affinity to Fc gamma receptor IIIa (FcyRIIIa) in immune cells. As such, antibody-dependent enhancement (ADE) could theoretically potentiate disease through antibodymediated enhanced viral infection and immune response (54, 55). Currently, the effect of the modified IgG Fc structure on the pathogenesis of COVID-19 remains unclear and needs further clarification. Regarding the cellular immune response, a subgroup of excessively activated and end-differentiated $\mathrm{CD}^{+}$ $\mathrm{T}$ cells with diminished function of antigen recognition overwhelmingly dominate in total $\mathrm{CD}^{+} \mathrm{T}$ cells (51). Longitudinal analysis of immune profiling of COVID-19 finds elevated plasma levels of IL-17A and IL-22 along with increased IL-17 secretion by $\mathrm{CD} 4^{+} \mathrm{T}$ cells in severe patients, indicative of promotive effects of Th17 cells in COVID-19 progression (22). Moreover, a previous observational study also confirms the pathologic role of Th17 cells in COVID-19 (41). These abnormal adaptive immune dynamics are likely to further fuel inflammation cascade and viral dissemination. Additionally, low expression of human leukocyte antigen-DR (HLA-DR) on CD14 
monocytes were detected in COVID-19 patients inversely correlating with a high circulating level of IL-6 (56), suggesting a sepsis-induced immunoparalysis. Moreover, a longitudinal study discovers a massive expansion of $\mathrm{T}$ cell-suppressing myeloid-derived suppressor cells in COVID-19 patients, accounting for $90 \%$ of total circulating mononuclear cells in severe cases and demonstrating a downward tendency along with recovery (57). The resultant immunodeficient state is likely to predispose COVID-19-infected patients to secondary bacterial and fungal infections in clinical course (3).

\section{POTENTIAL IMMUNOTHERAPIES FOR COVID-19}

\section{IL-6R Blockades}

The strong positive correlation between circulating IL-6 levels and illness severity in hospitalized COVID-19 patients provides the rationale for deployment of IL-6R inhibitors in a selection of infected patients. The most explored reagents that can neutralize IL-6 activity are the humanized monoclonal antibody (mAb) tocilizumab, and the fully human mAb sarilumab, which have previously shown benefits in patients with various rheumatic diseases, such as rheumatoid arthritis (RA), juvenile idiopathic arthritis (JIA), and adult-onset Still's disease (AOSD) (58). Current results from clinical studies evaluating IL-6R inhibitors in COVID-19 are inconsistent.

The first study includes 21 severe or critical patients treated with tocilizumab with no control group. All 21 patients received routine treatment for a week preceding tocilizumab therapy but exhibited sustained symptom deterioration. After treatment with tocilizumab, patients demonstrated absorbed lung lesions (90.5\%), decreased oxygen requirement (75\%), normalized lymphocytes (52.6\%), and improved clinical conditions (100\%) (59) (Table 2). Another study analyzed 15 COVID-19 patients with a median age of 73 years, encompassing mild $(n=2)$, severe $(n=6)$, and critical $(n=7)$ types. Ten patients had commodities, and 8 patients received concurrent methylprednisolone treatment. Despite tocilizumab mitigating the elevated CRP levels in all patients rapidly, only one patient achieved clinical improvement, nine were clinically stabilized, and two experienced disease deterioration. It is noteworthy that, instead of decreasing, a perpetuated and marked increase of IL-6 was observed in four patients with low pretreatment plasma IL-6 (16.4-73.6 pg/mL), who eventually succumbed or had disease aggravation (60). In addition, a clinical study from Italy analyzed 21 COVID-19 patients (median age 64 years) with ARDS. All patients were treated with siltuximab at doses ranging from 700 to $1200 \mathrm{mg}$ (median $900 \mathrm{mg}$ ) among whom 33\% of patients experienced an improved clinical condition, $43 \%$ of patients clinically stabilized, and $24 \%$ experienced condition deterioration (61). Roumier et al. report 30 selected patients (age $<80$ years, prior disease duration $>5$ days) with rapidly worsening (i.e., increase by more than $3 \mathrm{~L} / \mathrm{min}$ of oxygen flow within the previous $12 \mathrm{~h}$ ) severe COVID-19-associated pneumonia (62). In comparison with age-, gender-, and disease severity-matched control patients, tocilizumab strikingly reduced mechanical ventilation requirement and risk of subsequent ICU admission. Of note, a trend toward lower mortality, although no statistical difference, was observed in tocilizumab-treated patients. A single-center cohort study tested tocilizumab in patients with COVID-19 requiring mechanical ventilation, and the clinical outcomes of 78 patients who received tocilizumab with 76 well-matched tocilizumab-untreated controls were compared (63). Generally, the use of tocilizumab was associated with improved survival compared with tocilizumab-untreated patients. It is noteworthy that patients receiving tocilizumab treatment in this study were more inclined to develop superinfections than the tocilizumabuntreated controls ( $54 \%$ vs. $26 \% ; P<0.001)$ although there was no statistical difference in the 28-day case fatality rate between these two groups $(22 \%$ vs. $15 \% ; P=0.42)$. Potere et al. report a retrospective case-control study assessing the efficacy and safety of tocilizumab in COVID-19 patients with pneumonia, hyperinflammation, and hypoxemia requiring oxygen therapy (64). Forty eligible patients received tocilizumab treatment in addition to standard supportive care, and another 40 age- and sex-matched patients served as the control group only receiving standard of care. The results show that the application of tocilizumab resulted in good tolerance, improvement in oxygenation, less disease deterioration, and reduced CRP levels in tocilizumab-treated patients compared with the control group. Nevertheless, a case report found no beneficial therapeutic effect of tocilizumab on one severe COVID-19 patient with low pretreatment plasma IL-6 $(74.3 \mathrm{pg} / \mathrm{mL})$, who developed viral myocarditis and lymphopenia after receiving tocilizumab treatment (65).

Generally, many currently available clinical results regarding IL- 6 are conflicting and inconsistent, likely due to the differences in clinical trial designs although these data also suggest that disease severity and treatment time points may affect the therapeutic efficacy of IL-6R inhibitors on COVID-19. It should be particularly noted that IL- 6 has the dual function of suppressing or prompting viral replication in experimental model systems (85). IL-6 also plays key roles in tissue homeostatic and repair responses (86). The rebound from low pretreatment plasma IL- 6 levels in four patients may be a consequence of compensatory synthesis and release of IL-6. As such, the increase of IL- 6 to some extent may exert a beneficial effect on infected patients, especially in the later immunodeficient stage of COVID-19. Therefore, we recommend prudent use of IL-6-targeting therapies in concert with antiviral agents in patients with early, rapid, continuous deterioration as well as with clinical and laboratory proof of overactive inflammatory responses (i.e., rapidly aggravating state of breathing, shock, and elevations in IL-6 and CRP). Meanwhile, clinicians should be cautious of a possible IL-6 rebound, successive injuries, and the occurrence of probable infections secondary to IL-6-targeting therapy (87).

\section{Convalescent Plasma}

Convalescent plasma (CP) therapy, as a strategy of passive immunization, has been used in the containment of infectious 
TABLE 2 | Study types and characteristics of several clinical studies of immunotherapies.

\begin{tabular}{|c|c|c|c|c|c|}
\hline & Author & Study type & Single or multicenter & Disease severity & Sample size \\
\hline IL-6R blockades & Xu et al. (59) & Observational & Multicenter & Severe or critical & 21 treated \\
\hline Tocilizumab & Luo et al. (60) & Observational & Single center & Moderate, severe, and critical & 15 treated \\
\hline \multirow[t]{5}{*}{ Sarilumab } & Gritti et al. (61) & Observational & Single center & Complicated with ARDS & 21 treated \\
\hline & Roumier et al. (62) & Observational & Single center & Severe (rapidly deteriorating) & 30 treated +29 control \\
\hline & Somers et al. (63) & Observational & Single center & Severe & 78 treated +76 control \\
\hline & Potere et al. (64) & Observational & Single center & Severe & 40 treated +40 control \\
\hline & Radbel et al. (65) & Case series & Single center & Complicated with CRS & 2 treated \\
\hline \multirow[t]{7}{*}{ Convalescent plasma } & Duan et al. (66) & Case series & Single center & Severe & 10 treated \\
\hline & Shen et al. (67) & Case series & Single center & Critical (complicated with ARDS) & 5 treated \\
\hline & Zhang et al. (68) & Case series & Single center & Critical & 4 treated \\
\hline & Zeng et al. (69) & Observational & Multicenter & Critical & 6 treated +15 control \\
\hline & Salazar et al. (70) & Observational & Single center & Severe or critical & 25 treated \\
\hline & Li et al. (71) & $\mathrm{RCT}$ & Multicenter & Severe or life-threatening & 52 treated +51 control \\
\hline & Xia et al. (72) & Observational & Single center & Severe or critical & 138 treated +1430 control \\
\hline \multirow[t]{2}{*}{ IVIG } & Cao et al. (73) & Case series & Single center & Severe & 3 treated \\
\hline & Xie et al. (74) & Observational & Single center & Severe or critical & 58 treated \\
\hline \multirow[t]{2}{*}{ Thymosin alpha1 } & Liu et al. (75) & Observational & Multicenter & Severe & 36 treated +40 control \\
\hline & Yu et al. (51) & Observational & Single center & Severe or critical & 11 treated + 14 control \\
\hline \multirow[t]{7}{*}{ Corticosteroids } & Ling et al. (76) & Observational & Single center & Not mentioned & 5 treated +61 control \\
\hline & Zha et al. (77) & Observational & Multicenter & Mild & 11 treated +20 control \\
\hline & Wang et al. (78) & Observational & Single center & Confirmed COVID-19 & 73 treated +42 control \\
\hline & Wu et al. (79) & Observational & Single center & Complicated with ARDS & 50 treated +34 control \\
\hline & Yang et al. (80) & Case series & Single center & Complicated with CRS & 15 treated \\
\hline & Wang et al. (81) & Observational & Single center & Severe & 26 treated +20 control \\
\hline & Liu et al. (82) & Observational & Multicenter & Confirmed COVID-19 & 40 treated + 97 control \\
\hline \multirow[t]{3}{*}{ IFNs } & Zhou et al. (20) & Observational & Single center & Confirmed COVID-19 & 53 treated +24 control \\
\hline & Hung et al. (83) & RCT & Multicenter & Mild to moderate & 86 treated +41 control \\
\hline & Wang et al. (84) & Observational & Multicenter & Confirmed COVID-19 & 242 treated +204 control \\
\hline
\end{tabular}

ARDS, acute respiratory distress syndrome; COVID-19, corona virus disease 2019; CRS, cytokine release syndrome; IFNs, interferons; IL-6R, interleukin 6 receptor; IVIG, intravenous gammaglobulin; $R C T$, randomized controlled trial.

diseases since the early 20th century (88). CP demonstrated therapeutic benefits in several previous epidemics, including SARS, Middle East respiratory syndrome (MERS), and influenza A H1N1 virus infection (89-91). The protective effect of CP is mainly dependent on the amount and types of antibodies contained in the plasma of convalescent donors. Sufficient neutralizing Abs bind to a specific virus to impede its infectious power directly, thereby suppressing viremia (92). In addition, other nonneutralizing Abs may also confer benefits by exerting immunomodulatory effects. Studies show IgG transferred by plasma possesses anti-inflammatory capability regarding neutralizing cytokines, such as IL- $1 \beta$ and TNF- $\alpha$ (93). Other antibody-mediated pathways, such as complement activation, opsonization, and antibody-dependent cellular cytotoxicity, may also play a favorable role in CP therapy (94). Furthermore, anti-inflammatory cytokines, defensins, and other proteins involved in $\mathrm{CP}$ are expected to provide adjuvant therapeutic benefits for severely infected patients (95). In the rampantly spreading COVID-19 pandemic, CP is reevaluated in the absence of specific treatment, and the therapeutic effect of CP is generally encouraging.

Duan et al. report 10 severely ill COVID-19 patients transferred with $200 \mathrm{~mL}$ of $\mathrm{CP}$ with high neutralizing antibody titers from recently recovered donors (66). The median time from symptom onset to $\mathrm{CP}$ transfusion was 16.5 days. After receiving $\mathrm{CP}$ transfusion, all patients experienced improved clinical conditions by showing no symptoms or dramatically improved symptoms as well as the recovery of pulmonary lesions. Laboratory parameters are also inclined to improve, evidenced by increased lymphocyte count and decreased CRP levels in CP-treated patients. Notably, the SARS-CoV-2 viral load becomes undetectable in 7 patients receiving $\mathrm{CP}$ transfusion. Another uncontrolled case series analyzed 5 critically ill COVID-19 patients with ARDS in which all patients were treated between 10 and 22 days after admission with CP containing SARS-CoV-2 antibodies (titer > 1:1000) and a neutralization titer greater than 40 (67). All patients received antiviral agents and methylprednisolone before CP therapy. After CP treatment, four out of five patients displayed clinical improvements, including normalized body temperature, elevated $\mathrm{PaO}_{2} / \mathrm{FiO}_{2}$, and resolved ARDS. The decrement of viral loads to an undetectable level was also seen within 12 days after the transfusion. Of the same five patients, three have been discharged, and two have been clinically stabilized. Zhang et al. retrospectively describe four critically ill patients who were transfused with different amounts of CP (200-2400 ml) varying between 11 and 28 days after admission (68). Among the four patients, the time from transfusion to negative SARSCoV-2 RNA tests ranged from 3 to 22 days. All the patients recovered from the SARS-CoV-2 infection, including three discharged from the hospital and one transferred to unfenced ICU. Zeng et al. evaluate the efficacy of CP in 6 critically ill COVID-19 patients with respiratory failure (69). All infected patients received CP transfusion at a median of 21.5 days after the first detection of viral shedding. Although SARS-CoV-2 turned negative in all subjects by 3 days after initiating $\mathrm{CP}$ 
therapy, five out of six patients are deceased. In a study of 25 patients with severe and/or life-threatening COVID-19 disease, all patients received one $300-\mathrm{mL}$ dose of $\mathrm{CP}$ administrated at a median time of 10 days with 1 patient receiving a second transfusion 6 days after the initial transfusion (70). Most patients received concomitant anti-inflammatory agents and investigational antiviral treatments. On day 7 post-transfusion, 9 patients (36\%) had improved clinical status, and 7 patients were discharged. By 14 days post-transfusion, 19 patients (76\%) were clinically improved or discharged. Specifically, no adverse events pertinent to plasma transfusion were observed. In the newly reported randomized clinical trial of $\mathrm{CP}$ therapy for COVID-19 conducted in China, Li et al. tested the role of CP in severe (respiratory distress and/or hypoxemia) or lifethreatening (shock, organ failure, or requiring mechanical ventilation) COVID-19 patients with 52 randomized patients concurrently receiving standard care serving as the treatment group and another 51 randomized patients who received standard supportive care alone serving as controls (71). This randomized controlled trial involving 103 patients was originally planned to recruit 200 patients; however, the trial was terminated prematurely. Consequently, the clinical study was underpowered to some extent. In addition, there are no statistically significant differences pertaining to clinical improvement, discharge rate, and 28-day mortality rate between the CP-treated and control groups. Nonetheless, the report indeed indicates hopeful signals of CP therapy in COVID-19 patients, especially in severe types. The clinical improvement at 28 days occurred in 27 patients (51.9\%) in the CP group vs. 22 patients (43.1\%) in the control group (hazard ratio (HR), 1.40 [95\% CI, 0.79-2.49]; $P=0.26$ ). Negative SARS-CoV-2 conversion at $72 \mathrm{~h}$ occurred in $87.2 \%$ of the CP group vs. $37.5 \%$ of the control group (OR, 11.39 [95\% CI, 3.91-33.18]; $P<0.001)$. According to disease severity-oriented stratified analysis, in severe cases, the clinical improvement within 28 days occurred in $91.3 \%$ (21/23) of the CP group vs. $68.2 \%(15 / 22)$ of the control group (HR, 2.15 [95\% CI, 1.07 -4.32]; $P=0.03)$ although, in subjects with a life-threatening disease, it occurred in $20.7 \%(6 / 29)$ of the convalescent plasma group vs. $24.1 \%(7 / 29)$ of the control group (HR, 0.88 [95\% CI, $0.30-2.63$ ]; $P=0.83)$. In terms of the primary outcome, in severely ill patients, the time to clinical improvement within 28 days was 4.94 days shorter in the CP group relative to the control group (95\% CI, -9.33--0.54 days). Specifically, only 2 patients in the CP group experienced adverse events related to $\mathrm{CP}$ transfusion.

A single-center study reported on 1568 patients infected with severe or critical COVID-19 disease in Wuhan, of whom 138 patients received 200-1200 $\mathrm{ml} \mathrm{CP}$ transfusion depending on different clinical status and body weight, and another 1430 patients only received standard of care (72). CP treatment reduced the fatality rate by approximately $50 \%$ in the standard-treatment group (2.2\% vs. $4.1 \%)$. Encouragingly, CP therapy was associated with an increased percentage of lymphocytes and decreased percentage of neutrophils and CRP levels. Except for the decrease in total bilirubin, no serious adverse event associated with CP therapy was observed.
These six studies testing the therapeutic effectiveness of CP in COVID-19 are with limited controls and a relatively small sample size, which make them hard to be conclusive. The clinical trial conducted by $\mathrm{Li}$ et al. used a randomized trial design and recruited a relative larger sample size; however, it failed to acquire a statistically significant clinical improvement, possibly due to the early termination (71). Nevertheless, the therapeutic effectiveness of CP for COVID-19 reflected by these clinical trials are fairly hopeful, considering the majority of enrolled patients are in the advanced disease course with severe viremia. Moreover, it is generally recognized that viremia maximizes in the first week of infection in most viral illnesses; thus, an early CP infusion is likely to achieve the best therapeutic effect. However, a substantial number of infected patients in these studies failed to receive CP infusion until their disease progressed into severe or critical types. The protective effect of CP depends on the amount and types of antibodies. The possible mechanisms include viral neutralization and antibodydependent cellular cytotoxicity (94). Collectively, according to the currently available clinical data, $\mathrm{CP}$ was well tolerated in COVID-19 patients and has an acceptable safety profile.

\section{Intravenous Gamma Globulin}

Intravenous gamma globulin (IVIG) is a purified blood product containing polyclonal immunoglobulin $G$ prepared from thousands of healthy donors. It has long been used for treating a range of autoimmune and chronic inflammatory diseases, such as immune thrombocytopenic purpura (ITP), Kawasaki disease (KD), and primary immunodeficiency disease (96). Furthermore, in the past pandemic of influenza A H1N1 virus and the epidemics of SARS and MERS, application of IVIG alone or combined with other therapies is associated with the reduction of viral burden and various improvements in clinical outcomes (97-99). Currently, the experience from the application of IVIG in the treatment of SARS-CoV-2 infection is very limited.

Cao et al. report a case series of 3 patients with COVID-19 receiving a high dose of IVIG (0.3-0.5 g per kg weight per day) for 5 days (73). All 3 patients experienced varied elevations of inflammatory biomarkers (i.e., hsCRP, ESR). Furthermore, 2 patients exhibited lymphocytopenia, 1 patient displayed mild thrombocytopenia, and all 3 patients deteriorated into severe types before IVIG therapy. After infusion with IVIG, they all had normalized temperature within 2 days after treatment and alleviated respiratory symptoms within 5 days. None of them was reported with any adverse events. However, the effects of concurrent treatments, including antiviral agents and steroids, confounded the exact therapeutic effectiveness of IVIG. A retrospective study by Xie et al. explores the role of IVIG in severe and critically ill patients (74). The study included 58 severely or critically infected patients. All patients received supportive care and antiviral treatments. Once the absolute lymphocyte count fell below $0.5 \times 10^{9} / \mathrm{L}$, they commenced with IVIG infusion ( $20 \mathrm{~g} /$ day) and correction for hypoalbuminemia. The study shows that the use of IVIG within $48 \mathrm{~h}$ could significantly reduce the 28-day mortality rate, ventilator requirement, and hospital and ICU stay 
although an earlier use of IVIG within $24 \mathrm{~h}$ after admission did not make any statistical difference in terms of the 14- or 28-day mortality rates, suggesting the importance of choosing the appropriate initiation time for IVIG therapy.

The anti-inflammatory and immune-modulatory properties of IVIG provide the rationale for its use in patients with SARSCoV-2 infection. The possible mechanisms facilitating restoration of immune homeostasis through IVIG include blocking multiple proinflammatory cytokines by autoreactive antibodies, blocking activating Fc $\gamma \mathrm{R}$ on innate immune effector cells, suppressing pathogenic Th1 and Th17 subsets, and expanding regulatory $\mathrm{T}$ cells $(100,101)$. Additionally, a mouse model study shows that IVIG could reduce gut inflammation; the beneficial effect is related to the suppression of IL- 6 and the enhancement of IL-10 in the gut (102). A recent case report shows that a severe COVID-19 patient with sustained diarrhea recovered after the treatment of intensive plasma exchange and IVIG (103). The amelioration of respiratory symptoms and diarrhea is, at the least, attributable to the immuno-regulatory effect of IVIG. However, a clear demonstration of effectiveness and safety of IVIG requires well-controlled clinical studies.

\section{Thymosin Alpha1}

Thymosin alpha1 (T $\alpha 1)$ is a kind of endogenous polypeptide first isolated from the thymic tissue, and it has been applied in multiple debilitating diseases ranging from cancers and autoimmune disorders $(104,105)$ to viral infectious diseases (106). T $\alpha 1$ is demonstrated to have immune-regulatory effects, including enhancing the production of T cells, the level of HDR, and anti-inflammatory cytokine IL-10 while decreasing proinflammatory cytokine TNF- $\alpha(107,108)$. Considering the ubiquity of lymphocytopenia in patients infected with COVID19 and its deleterious effects, the adjuvant use of T $\alpha 1$ might yield some therapeutic benefits through prompting $\mathrm{T}$ cell production.

Liu et al. retrospectively report on 76 severe or critical COVID-19 patients with 36 patients receiving treatment of T $\alpha 1$ and 40 nontreated patients serving as a control group (75). T $\alpha 1$-treated patients were given subcutaneous injections of T $\alpha 1$ (10 mg once per day) for at least 7 consecutive days. In comparison with the nontreated patients, T $\alpha 1$ significantly reduced the mortality rate of infected patients, and effectively restored $\mathrm{T}$ cell numbers in patients with severe lymphocytopenia $\left(\mathrm{CD}^{+} \mathrm{T}\right.$ cells $<400 / \mu \mathrm{L}, \mathrm{CD} 4^{+} \mathrm{T}$ cells $\left.<650 / \mu \mathrm{L}\right)$. Furthermore, it is noteworthy that patients older than 60 years or with underlying comorbidities of hypertension or cardiovascular diseases, also exhibited an enhancement of $\mathrm{CD}^{+} \mathrm{T}$ and $\mathrm{CD} 4^{+}$ $\mathrm{T}$ cells. In additio, T $\alpha 1$ refrains $\mathrm{T}$ cells from exhaustion mirrored by the decreased expression of exhausted markers involving programmed death-1 (PD-1) and T cell immunoglobulin and mucin domain protein 3 (Tim-3) on $\mathrm{CD}^{+} \mathrm{T}$ cells post $\mathrm{T} \alpha 1$ therapy. T $\alpha 1$ exerts its promotional effect on the restoration of $\mathrm{CD}^{+} \mathrm{T}$ and $\mathrm{CD} 4^{+} \mathrm{T}$ cells through boosting thymus output. No adverse event related to T $\alpha 1$ was reported. Yu et al. performed single-cell transcriptomic analysis of peripheral lymphocytes from 10 patients at different stages of the disease and found abnormal dynamics of adaptive immune cells (51). Prothymosin alpha (PTMA), the proprotein of T $\alpha 1$, was significantly expressed in a subset of stem-like $C D 8^{+} T$ memory cells with a highly proliferating feature and low expressed on a cluster of dysfunctional and overactivated $C D 8^{+} T$ cells. In subsequent in vitro tests, T $\alpha 1$ dramatically increased T cell numbers on days 6 and 9 compared with the untreated group. Furthermore, T $\alpha 1$ reduced the production of IFN $\gamma$ and TNF $\alpha$ although not statistically significantly.

In general, the reports regarding the effectiveness of T $\alpha 1$ in COVID-19 are pretty limited although T $\alpha 1$ was clinically applied as an adjuvant therapy in severely or critically infected patients at the beginning of the SARS-CoV-2 outbreak. To date, the preliminary results of T $\alpha 1$ for treating COVID-19 revealed by the only two available clinical studies are greatly encouraging. The equilibrium of the adaptive immune system is of paramount importance. Sufficient capability to eradicate viral invasion and restrain excessive secretion of inflammatory cytokines constitute an efficient adaptive immune response to SARS-CoV-2. As shown by $\mathrm{Yu}$ et al., T $\alpha 1$ could restore $\mathrm{T}$ cell numbers, which are essential for viral clearance, concomitant with decreased production of IFN $\gamma$ and TNF- $\alpha$ in the case of formation of a deleterious inflammation cascade (51). Hence, T $\alpha 1$ is a promising treatment option for COVID-19 patients, especially for those who manifest severe lymphocytopenia.

\section{Corticosteroids}

In clinical settings, corticosteroids have been empirically administrated in COVID-19 patients, especially in critical cases with rapid disease deterioration (38). Corticosteroids are a major medication of immunomodulatory therapy functioning by potent anti-inflammatory and antifibrotic capabilities, and they have been widely used as an auxiliary therapy in the treatment of ARDS; sepsis; and viral infectious diseases, such as SARS, MERS, and influenza (109-111). However, clinical results on the role of corticosteroids are discrepant, and the controversial situation still persists in SARS-CoV-2 infection.

A retrospective study involved 113 inpatients, 56.6\% of whom received relatively low corticosteroid dosing $(0.5-1.0 \mathrm{mg}$ methylprednisolone/kg body weight) (112). Analysis indicates that corticosteroid treatment is related to prolonged SARS-CoV2 RNA shedding but does not serve as an independent risk factor. Similarly, in another study, 5 patients treated with corticosteroids displayed longer duration of viral RNA detection compared with the non-glucocorticoid treatment group, indicative of delayed virus clearance induced by corticosteroid treatment (76). However, according to a cohort study including 120 noncritical inpatients (54/120 receiving corticosteroid therapy), corticosteroid treatment is unrelated to prolonged SARS-CoV-2 RNA shedding (113). The result is in parallel with an observational study showing no association between corticosteroid treatment and virus clearance time (77). In this report, 11 of 31 mild COVID-19 patients were administrated with corticosteroids (40 mg methylprednisolone once or twice per day) within $24 \mathrm{~h}$ of admission for a median 5 days. In addition to unaffected virologic outcomes, corticosteroid treatment did not influence the length of hospital stay and duration of symptoms in mild cases. According to a cohort study, severe COVID-19 infected patients were more inclined to 
receive corticosteroid treatment compared with nonsevere patients (114). Furthermore, high-dose corticosteroid use (maximum dose $\geq 1 \mathrm{mg} / \mathrm{kg} / \mathrm{d}$ prednisone) was related to a high risk of death in severe cases. Another observational study did not support the usage of corticosteroids as corticosteroid treatment was significantly associated with adverse outcomes of either mortality or ICU admission (78). After adjusting for confounding factors on outcomes, although no statistical significance was observed, a 2.155 -fold increase in risk in either mortality or ICU admission was observed in corticosteroid-treated patients in comparison with noncorticosteroid-treated patients.

Several clinical studies also report beneficial effects of corticosteroid treatment on COVID-19 patients. A cohort study including 84 COVID-19 patients with ARDS indicates that corticosteroid therapy may lead to significant mortality reduction compared to non-corticosteroid therapy $(46.0 \%$ vs. $61.8 \%)$ in seriously ill COVID-19 patients with ARDS (79). Additionally, a case series report involving 15 ICU patients showed corticosteroid therapy was related to a reduced requirement for vasopressor, improved oxygenation, and decreased CRP levels in critical patients (80). Of note, the enrolled 15 patients all developed respiratory failure with progressing increased inflammatory markers, suggesting the potential benefit of corticosteroids in critical types with hyperinflammation. Moreover, the application of corticosteroids in an early, low-dose, and short-term strategy have demonstrated favorable effects on 26 patients with severe COVID-19 pneumonia (81). In this study, methylprednisolone was intravenously administrated at a dosage of $1-2 \mathrm{mg} / \mathrm{kg} / \mathrm{d}$ for $5-7$ days. Compared with those without methylprednisolone administration, patients receiving methylprednisolone treatment presented with more rapid temperature normalization, faster oxygenation improvement, and better lung radiography. Nonetheless, in another observational study including 137 patients, small dosage of methylprednisolone (30-80 $\mathrm{mg} /$ day) failed to rescue a cluster of COVID-19 patients with short-term disease progression (82). Forty patients administrated with methylprednisolone did not show a shortened disease course or an improved clinical outcome, and some even displayed aggravated lung images after methylprednisolone therapy.

British researchers have announced surprising results in an evaluation of corticosteroids for treating COVID-19 in the recovery trial (115). In this recently published, large-scale, controlled, open-label trial, 2104 patients were assigned to receive oral or intravenous dexamethasone treatment (at a dose of $6 \mathrm{mg}$ once daily) for up to 10 days, and 4321 patients received usual care. Generally, application of dexamethasone in hospitalized COVID-19 patients led to lower 28-day mortality than the usual care $(22.9 \%$ vs. $25.7 \%$; $P<0.001)$. Furthermore, clinical benefits of dexamethasone were closely associated with respiratory support. Receipt of dexamethasone was associated with lower mortality rates in comparison with the usual care group among patients requiring invasive mechanical ventilation (29.3\% vs. $41.4 \%)$ and in those receiving supplemental oxygen in other ways ( $23.3 \%$ vs. $26.2 \%)$. Nonetheless, there was a trend showing a seemingly harmful effect of dexamethasone treatment among patients without respiratory support (17.8\% vs. $14.0 \%)$. Importantly, dexamethasone seemed to confer a clear benefit in patients treated for more than 7 days after symptom onset when the lung damage commonly developed. Additionally, dexamethasone treatment also demonstrated more therapeutic benefits than usual care in terms of duration of hospital stay (median, 12 vs. 13 days), probability of discharge alive within 28 days, and risk of progression to invasive mechanical ventilation.

At present, clinical observational studies evaluating the efficacy and safety of corticosteroids in COVID-19 are highly contested and limited by their small sample sizes as well as nonrandomized nature. Therefore, a concrete conclusion about corticosteroid application in the treatment of SARS-CoV-2 infection still cannot be made. According to the aforementioned studies, corticosteroid administration was more common in severe and critical patients in clinical practice; thus, it is more likely that disease severity, rather than the use of corticosteroids, predisposes COVID-19 patients to a high risk of death. In addition, the therapeutic effects of corticosteroids are seemingly affected by the heterogeneity of dosing regimens, duration, and initiation timing of therapy. Encouragingly, corticosteroid therapy has demonstrated therapeutic benefits in COVID-19 patients requiring respiratory support (115) and in a subset of critical patients with ARDS (79), which indicates rational and prudent corticosteroid usage might yield favorable outcomes in patients experiencing respiratory disorders. Given the intertwined hyperinflammatory and immunocompromised stages in the COVID-19 disease course, a short-term and low-dose application of corticosteroids promoting the formation of a disastrous cytokine storm is likely to rescue seriously ill patients from disease aggravation. Considering potential adverse events elicited by corticosteroid therapy, such as hyperglycemia, secondary infection, and osteonecrosis (111, 116), the low-dose administration of corticosteroids for a short duration is needed with simultaneously close monitoring.

\section{IFNs}

IFNs are critical components of the immediate antiviral response. IFNs are classified into three classes, comprising a plethora of type-I IFNs (IFN- $\alpha$, IFN- $\beta$, IFN- $\epsilon$, IFN- $\kappa$, IFN- $\omega$ in humans), type-II species (IFN- $\gamma$ ), and type-III IFNs (IFN- $\lambda$ ). IFNs could be distinguished by the surface receptors to which they bind. Type-I IFNs bind to IFN- $\alpha / \beta$ receptors (IFNAR), which are widely distributed in body cells; type-II IFNs bind to the IFN- $\gamma$ receptor (IFNGR); and type-III IFNs signal through type-III IFN receptors (IFNLR) only expressed on epithelial cells and certain myeloid cells, including neutrophils and human B cells (117). All IFNs are considered to have antiviral effects (118). As mentioned, early and sufficient secretion of type-I IFNs is recognized as beneficial for the control of SARS-CoV-2. Concordantly, Bastard et al. report that individuals who had neutralizing autoantibodies (auto-Abs) to type-I IFNs are more susceptible to develop critical types of COVID-19 once infected by SARS-CoV-2 as the auto-Abs could weaken the ability of type-I IFNs to achieve viral clearance (49). 
Of note, the majority of patients (95 of the 101) with auto-Abs are men, which may explain why being male is a risk factor for life-threatening COVID-19.

In previous in vivo and in vitro studies of viral infectious diseases, type-I IFNs alone or in combination with other antiviral agents have displayed promising efficacy; however, negative results also exist. In a marmoset model study of MERS, the combination treatment of IFN- $\beta 1 \mathrm{~b}$ with lopinavir/ritonavir reduced viral load and lung abnormalities (119). Similarly, the prophylactic administration of IFN- $\alpha 2 b$ was reported to protect type-1 pneumocytes against SARS coronavirus infection and reduce viral replication in macaques (120). Clinical usage of IFN-a combined with corticosteroids led to better outcomes, including improved oxygen saturation and rapid resolution of lung lesions (121). The application of IFN- $\alpha 2$ a combined with ribavirin in MERS patients delayed mortality, whereas it failed to maintain efficacy with a late initiation (122). In another cohort study, the IFN-ribavirin combination was not significantly associated with improved outcomes in patients with MERS (89). Low concentrations of type-I IFNs in severely ill patients with COVID-19 are recognized as a prognostic factor for poor outcomes (20). Thus, it is reasonable to consider adding type-I IFNs to the treatment of COVID-19. Indeed, type-I IFNs and other antiviral therapies have already demonstrated some therapeutic benefits in COVID-19. In a retrospective study of 77 COVID-19 patients, treatment with IFN- $\alpha 2 b$ with or without arbidol substantially reduced the duration of viral shedding and inflammatory markers, including IL-6 and CRP (20). Furthermore, according to a very recently reported phase II clinical trial, in comparison with monotherapy of lopinavirritonavir, a triple combination therapy of IFN- $\beta 1$, lopinavirritonavir, and ribavirin in mild-to-moderate COVID-19 patients was associated with the shortened duration of viral shedding, reduced length of hospital stay, and improved clinical symptoms (83). Also, a retrospective multicenter cohort study compared patients who received IFN therapies with those who did not receive IFNs and found association of early IFN-a2b administration ( $<5$ days after admission) with a significantly reduced mortality rate in severe-to-critical cases of COVID-19 although late IFN use was associated with prolonged hospital stay and slower improvement of CT scan compared with nonIFN therapy (84).

IFN- $\gamma$ has been investigated in various allergic diseases with relatively good safety profiles (123). In addition to antiviral effects, IFN- $\gamma$ is also shown to have a potent immunomodulatory property (124). In a SARS-CoV infected mouse model, intraperitoneal IFN- $\gamma$ injection effectively protected adult mice against lethal injury (125). Bellomi et al. also report IFN- $\gamma$ and IFN- $\beta$ could synergistically counter against SARS-CoV infection on Vero cells (126). Importantly, IFN- $\gamma$ in concert with IL- 4 is shown to downregulate the expression of ACE2 on SARS-CoV-infected cells in vitro (127), suggestive of its potentially inhibitory activity on SARS$\mathrm{CoV}$ infection.

IFN- $\lambda$ has recently obtained much attention and serves as a promising treatment option for COVID-19 by virtue of its distinctive mode of action. Because of the restricted expression of IFNLR, IFN- $\lambda$ is proposed to exert sustained guarding effects on epithelial cells without a deleterious systemic inflammatory effect, which may be a great concern for IFN-I application. Of note, in a newly developed mouse model of SARS-CoV-2 infection, both prophylactic and therapeutic administration of IFN- $\lambda$ inhibited viral replication in mice (128). However, a recent study investigated the roles of type-III IFNs on lung physiology and surprisingly found that IFN $-\lambda$ could contribute to the disruption of the lung barrier and increase the risk of lethal bacterial superinfections (129). Likewise, another study indicated potential harm of IFN- $\lambda$ for pulmonary epithelia, which also reported that the exacerbated and prolonged production of IFNs, including IFN- $\alpha / \beta$ and IFN- $\lambda$, hampered lung epithelial proliferation. IFN $-\lambda$ shows the most potent deleterious effect (130). Additionally, the sustained and highly elevated plasma levels of IFN- $\alpha$ and IFN- $\lambda$ were observed in patients who died of SARS-CoV-2 infection (22). Thus, we should stay cautious about the application of IFNs in case of resultant adverse events.

Once antiviral therapies armed by IFNs are considered, the initiation time of IFN therapy is of utmost importance. Early administration preceding the peak of viremia or prophylactic treatment may confer maximal protection without substantial pathology. In addition, regarding possible adverse events, close scrutiny of hallmarks in inflammation and lung function is necessary.

\section{Vaccine}

Despite several immunotherapies demonstrating their therapeutic benefits in the clinical context of controlling COVID-19, there is an urgent need to develop effective vaccines specific against SARS-CoV-2. An effective vaccine could confer individuals the ability to develop immunity to SARS-CoV-2 before being exposed to the virus. Currently, companies and institutions worldwide have taken the initiative of developing vaccines against COVID-19 based on various molecular platforms, such as inactivated virus, live attenuated virus, viral protein subunit, viral nucleic acid, peptide, viral vector (replicating and nonreplicating), and virus-like particle (131). As of early December, there are 13 vaccines that reached phase 3 efficacy trials, of which, mRNA-1273 encodes stabilized prefusion S proteins of SARS-CoV-2 and is embedded in lipid nanoparticles (132). Solicited adverse effects include fever, fatigue, headache, muscle ache, and pain at the injection site (132). Delivery of the antigen into human cells could stimulate the body to produce virus-specific T and B cells. Once the SARSCoV-2 invasion in encountered in the future, memory $\mathrm{T}$ cells rapidly respond to SARS-CoV-2, and memory B cells produce neutralizing antibodies against the virus, thus protecting healthy individuals from COVID-19. Ad5-nCoV is a nonreplicating viral vector vaccine that uses replication-defective adenovirus type 5 as a vector to express $\mathrm{S}$ protein, the adverse effects of which are generally moderate, including fever, pain, and fatigue (133). AZD1222 (ChAdOx1-S) is a nonreplicating viral vector vaccine expressing the SARS-CoV-2 $\mathrm{S}$ protein with no severe adverse effects (134), and NVX-CoV2373 is a SARS-CoV-2 recombinant spike protein nanoparticle with adjuvant, the 


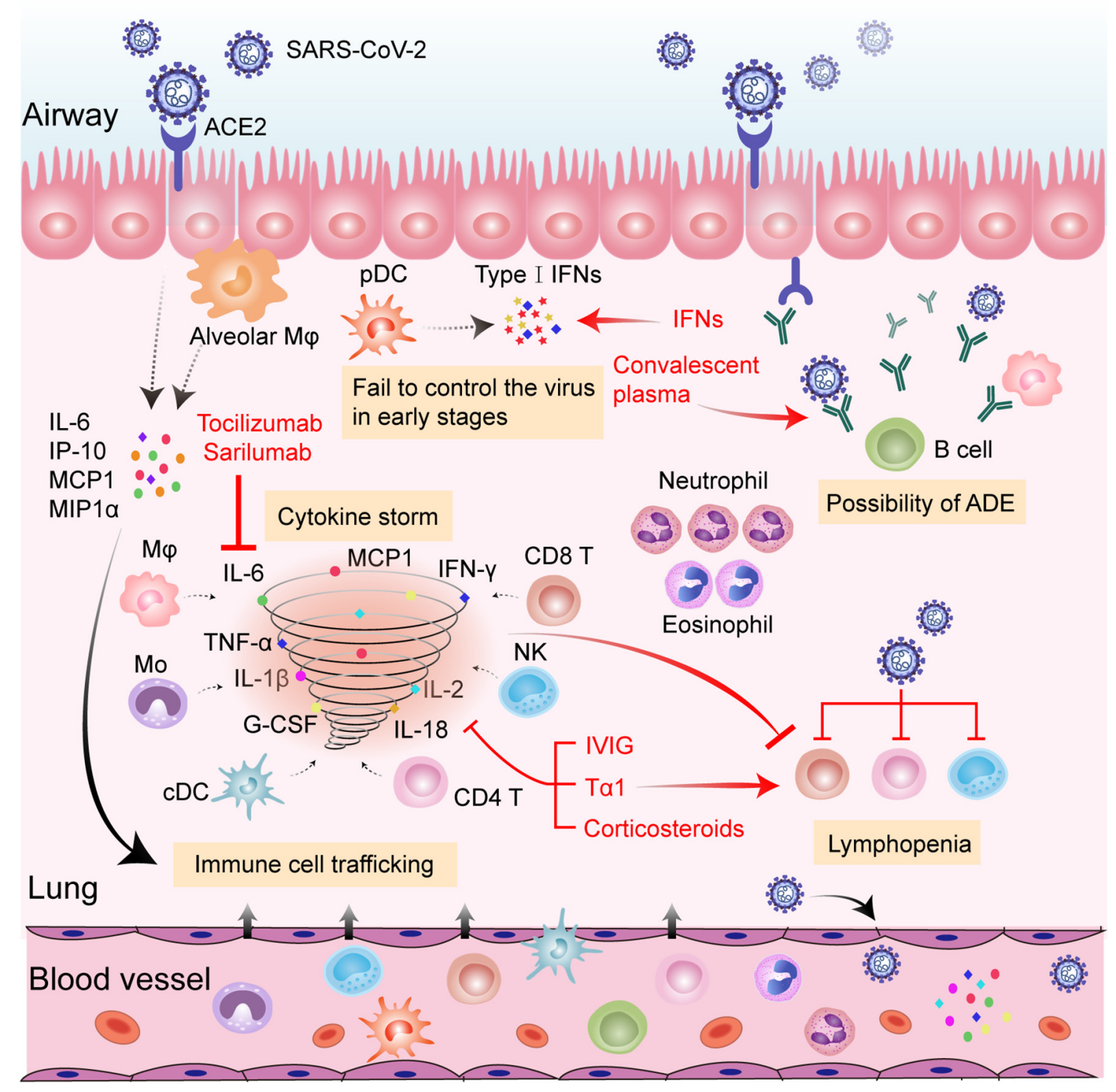

FIGURE 1 | Hypothesized immunopathology of severe SARS-CoV-2 infection and possible therapeutic targets of anti-COVID-19 immunotherapies. SARS-CoV-2 infects pulmonary epithelial cells through binding to ACE2. Viral infection and replication destroy infected lung cells, inducing the release of numerous cytokines and chemokines (i.e., IL-6, IP-10, MCP1, and MIPl $\alpha$ ) from neighboring epithelial cells and alveolar M $\varphi$. The released proteins recruit a variety of innate and adaptive immune cells to the inflamed site among which, pDCs are the main source of type-I IFNs. The failure of type-I IFNs to successfully control SARS-CoV-2 in the early stages fuels the viral dissemination to other organs and tissues. Monocytes, M $\varphi$, cDCs, NK cells, CD4 ${ }^{+} \mathrm{T}$ cells, and CD8 ${ }^{+} \mathrm{T}$ cells further secrete inflammatory cytokines (including IL-1 $\beta$, IL-2, IL-6, IL-18, TNF- $\alpha$, G-CSF, IFN- $\gamma$, etc.) and promote the cascade of inflammatory processes. Amounts of neutrophils and eosinophils are attracted to the site of infection and may cause damage to the lungs. Virus-induced lymphocyte disruption and sequestration in the lung lesion, along with inflammatory cytokine-induced lymphocyte apoptosis, may result in lymphopenia in the circulation. Non-neutralizing antibodies produced by B cells may enhance viral infection and potentiate immune responses through ADE. Tocilizumab and sarilumab could neutralize IL-6 activity, thus reducing inflammation. CP confers

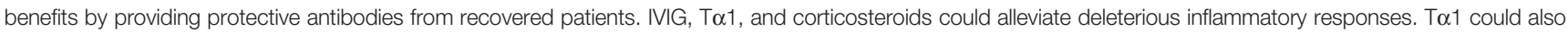
prompt T cell production. Addition of IFNs could confer antiviral effects. Abbreviations: ACE2, angiotensin-converting enzyme 2; ADE, antibody-dependent enhancement; CDC, conventional dendritic cells; G-CSF, granulocyte-colony stimulating factor; IFN- $\gamma$, interferon gamma; IL, interleukin; IP-10, interferon-inducible protein-10; IVIG, intravenous gamma globulin; MCP-1, monocyte chemotactic protein 1; MIPl $\alpha$, macrophage inflammatory protein-1 $\alpha$; Mo, monocyte; M macrophage; NLR, neutrophil-to-lymphocyte; NK, natural killer cell; pDC, plasmacytoid dendritic cells; SARS-CoV-2, severe acute respiratory syndrome coronavirus 2; T $\alpha$ 1, Thymosin alpha1; TNF- $\alpha$, tumor necrosis factor alpha. 
reported adverse events of which were mild (135). Despite the vaccines under development varying in types and mechanisms of action, they are all aimed to give instructions on how to build robust immunity to fight against SARS-CoV-2.

\section{CONCLUDING REMARKS}

The rapid diffusion of COVID-19 has posed a huge threat to public health and the world economy. The continued occurrence and refraction of severe and critical cases further overwhelms the intensive care system. Although our understanding of the immune pathogenesis of COVID-19 is still very limited, it is generally recognized that a disordered immune response is the determinant of the severe types. Hallmarks of hyperinflammation in concert with reduced and dysfunctional lymphocytes are observed in a cluster of severe or critical patients, contributing to ARDS and multiorgan failures. Moderately enhanced cytokines and effectual adaptive immune cells are equally important to successful viral elimination and homeostasis restoration. Thus, exploring a balance between anti-inflammation and maintenance of immune function is vital when considering the initiation of immunotherapies. Protection from excessive inflammation in organs should not be at the expense of immunity. In addition, individually tailored immunotherapy initiated at the right time window could yield maximum therapeutic benefits (Figure 1). In the very early stage of COVID-19, the application of antiviral

\section{REFERENCES}

1. The Novel Coronavirus Pneumonia Emergency Response Epidemiology T. The Epidemiological Characteristics of an Outbreak of 2019 Novel Coronavirus Diseases (COVID-19) - China, 2020. China CDC Weekly (2020) 2(8):113-22. doi: 10.46234/ccdcw2020.032

2. Chen G, Wu D, Guo W, Cao Y, Huang D, Wang H, et al. Clinical and immunological features of severe and moderate coronavirus disease 2019. J Clin Invest (2020) 130(5):2620-9. doi: 10.1172/jci137244

3. Chen N, Zhou M, Dong X, Qu J, Gong F, Han Y, et al. Epidemiological and clinical characteristics of 99 cases of 2019 novel coronavirus pneumonia in Wuhan, China: a descriptive study. Lancet (London England) (2020) 395 (10223):507-13. doi: 10.1016/s0140-6736(20)30211-7

4. Chen T, Wu D, Chen H, Yan W, Yang D, Chen G, et al. Clinical characteristics of 113 deceased patients with coronavirus disease 2019: retrospective study. BMJ (Clin Res ed) (2020) 368:m1091. doi: 10.1136/bmj.m1091

5. Xu PP, Tian RH, Luo S, Zu ZY, Fan B, Wang XM, et al. Risk factors for adverse clinical outcomes with COVID-19 in China: a multicenter, retrospective, observational study. Theranostics (2020) 10(14):6372-83. doi: $10.7150 /$ thno.46833

6. Chan JF, Kok KH, Zhu Z, Chu H, To KK, Yuan S, et al. Genomic characterization of the 2019 novel human-pathogenic coronavirus isolated from a patient with atypical pneumonia after visiting Wuhan. Emerg Microbes Infect (2020) 9(1):221-36. doi: 10.1080/22221751.2020.1719902

7. Xia H, Cao Z, Xie X, Zhang X, Chen JY-C, Wang H, et al. Evasion of Type I Interferon by SARS-CoV-2. Cell Rep (2020) 33(1). doi: 10.1016/ j.celrep.2020.108234

8. Zhou P, Yang XL, Wang XG, Hu B, Zhang L, Zhang W, et al. A pneumonia outbreak associated with a new coronavirus of probable bat origin. Nature (2020) 579(7798):270-3. doi: 10.1038/s41586-020-2012-7

9. Sungnak W, Huang N, Bécavin C, Berg M, Queen R, Litvinukova M, et al. SARS-CoV-2 entry factors are highly expressed in nasal epithelial cells agents with $\mathrm{T} \alpha 1$ is recommended in case of a vicious inflammatory cascade to reduce the viral burden and strengthen immunity. For a subset of rapidly deteriorating infected patients with hallmarks of uncontrolled proinflammatory responses, antiinflammatory treatments, such as cytokine-targeted therapies, might be beneficial by suppressing hyperinflammation-induced injuries. Meanwhile, close monitoring of adaptive immune function is indispensable. Further immune-related studies about COVID-19 are necessary for guiding rapid disease stratification and well-orchestrated immunotherapies.

\section{DATA AVAILABILITY STATEMENT}

The original contributions presented in the study are included in the article/supplementary material, further inquiries can be directed to the corresponding authors.

\section{AUTHOR CONTRIBUTIONS}

BX and JZ performed the study design, data collection, data analysis, data interpretation, and writing. YL performed the data collection and data analysis. YS and SY performed the study design, data interpretation, and writing. All authors contributed to the article and approved the submitted version. together with innate immune genes. Nat Med (2020) 26(5):681-7. doi: 10.1038/s41591-020-0868-6

10. Ulrich H, Pillat MM. CD147 as a Target for COVID-19 Treatment: Suggested Effects of Azithromycin and Stem Cell Engagement. Stem Cell Rev Rep (2020) 16(3):434-40. doi: 10.1007/s12015-020-09976-7

11. Jamilloux Y, Henry T, Belot A, Viel S, Fauter M, El Jammal T, et al. Should we stimulate or suppress immune responses in COVID-19? Cytokine and anti-cytokine interventions. Autoimmun Rev (2020) 19(7):102567. doi: 10.1016/j.autrev.2020.102567

12. Kuipers MT, van der Poll T, Schultz MJ, Wieland CW. Bench-to-bedside review: Damage-associated molecular patterns in the onset of ventilator-induced lung injury. Crit Care (London England) (2011) 15(6):235. doi: 10.1186/cc10437

13. Diebold SS, Kaisho T, Hemmi H, Akira S, Reis e Sousa C. Innate antiviral responses by means of TLR7-mediated recognition of single-stranded RNA. Sci (N Y NY) (5663) 2004) 303:1529-31. doi: 10.1126/science.1093616

14. Medzhitov R. Recognition of microorganisms and activation of the immune response. Nature (2007) 449(7164):819-26. doi: 10.1038/nature06246

15. Felsenstein S, Herbert JA, McNamara PS, Hedrich CM. COVID-19: Immunology and treatment options. Clin Immunol (2020) 215:108448-. doi: 10.1016/j.clim.2020.108448

16. Liu S, Cai X, Wu J, Cong Q, Chen X, Li T, et al. Phosphorylation of innate immune adaptor proteins MAVS, STING, and TRIF induces IRF3 activation. Sci (N Y NY) (2015) 347(6227):aaa2630. doi: 10.1126/science.aaa2630

17. Sa Ribero M, Jouvenet N, Dreux M, Nisole S. Interplay between SARS-CoV2 and the type I interferon response. PloS Pathog (2020) 16(7):e1008737-e. doi: 10.1371/journal.ppat.1008737

18. Thompson MR, Kaminski JJ, Kurt-Jones EA, Fitzgerald KA. Pattern recognition receptors and the innate immune response to viral infection. Viruses (2011) 3(6):920-40. doi: 10.3390/v3060920

19. Blanco-Melo D, Nilsson-Payant BE, Liu WC, Uhl S, Hoagland D, Møller R, et al. Imbalanced Host Response to SARS-CoV-2 Drives Development of COVID-19. Cell (2020) 181(5):1036-45. doi: 10.1016/j.cell.2020.04.026 
20. Zhou Q, Chen V, Shannon CP, Wei XS, Xiang X, Wang X, et al. Interferon$\alpha 2 b$ Treatment for COVID-19. Front Immunol (2020) 11:1061. doi: 10.3389/ fimmu.2020.01061

21. Zhou Z, Ren L, Zhang L, Zhong J, Xiao Y, Jia Z, et al. Heightened Innate Immune Responses in the Respiratory Tract of COVID-19 Patients. Cell Host Microbe (2020) 27(6):883-90.e2. doi: 10.1016/j.chom.2020.04.017

22. Lucas C, Wong P, Klein J, Castro TBR, Silva J, Sundaram M, et al. Longitudinal analyses reveal immunological misfiring in severe COVID-19. Nature (2020) 584(7821):463-9. doi: 10.1038/s41586-020$2588-y$

23. Kindler E, Thiel V, Weber F. Interaction of SARS and MERS Coronaviruses with the Antiviral Interferon Response. Adv Virus Res (2016) 96:219-43. doi: 10.1016/bs.aivir.2016.08.006

24. Thoms M, Buschauer R, Ameismeier M, Koepke L, Denk T, Hirschenberger M, et al. Structural basis for translational shutdown and immune evasion by the Nsp1 protein of SARS-CoV-2. Sci (N Y NY) (2020) 369(6508):1249-55. doi: $10.1126 /$ science.abc8665

25. Jones SA, Jenkins BJ. Recent insights into targeting the IL- 6 cytokine family in inflammatory diseases and cancer. Nat Rev Immunol (2018) 18(12):77389. doi: 10.1038/s41577-018-0066-7

26. Rose-John S. The Soluble Interleukin 6 Receptor: Advanced Therapeutic Options in Inflammation. Clin Pharmacol Ther (2017) 102(4):591-8. doi: $10.1002 /$ cpt.782

27. Gao Y, Li T, Han M, Li X, Wu D, Xu Y, et al. Diagnostic utility of clinical laboratory data determinations for patients with the severe COVID- 19. J Med Virol (2020) 92(7):791-6. doi: 10.1002/jmv.25770

28. Zhou F, Yu T, Du R, Fan G, Liu Y, Liu Z, et al. Clinical course and risk factors for mortality of adult inpatients with COVID-19 in Wuhan, China: a retrospective cohort study. Lancet (London England) (2020) 395 (10229):1054-62. doi: 10.1016/s0140-6736(20)30566-3

29. Leisman DE, Ronner L, Pinotti R, Taylor MD, Sinha P, Calfee CS, et al. Cytokine elevation in severe and critical COVID-19: a rapid systematic review, meta-analysis, and comparison with other inflammatory syndromes. Lancet Respiratory Med (2020) 8(12):1233-44. doi: 10.1016/s2213-2600(20) 30404-5

30. Liu J, Liu Y, Xiang P, Pu L, Xiong H, Li C, et al. Neutrophil-to-lymphocyte ratio predicts critical illness patients with 2019 coronavirus disease in the early stage. J Trans Med (2020) 18(1):206. doi: 10.1186/s12967-020-02374-0

31. Feng Z, Diao B, Wang R, Wang G, Wang C, Tan Y, et al. The Novel Severe Acute Respiratory Syndrome Coronavirus 2 (SARS-CoV-2) Directly Decimates Human Spleens and Lymph Nodes. medRxiv (2020), 2020.03.27.20045427. doi: 10.1101/2020.03.27.20045427

32. Zhou Y, Fu B, Zheng X, Wang D, Zhao C, Qi Y, et al. Pathogenic T-cells and inflammatory monocytes incite inflammatory storms in severe COVID-19 patients. Natl Sci Rev (2020) 7(6):998-1002. doi: 10.1093/nsr/nwaa041

33. Wen W, Su W, Tang H, Le W, Zhang X, Zheng Y, et al. Immune cell profiling of COVID-19 patients in the recovery stage by single-cell sequencing. Cell Discovery (2020) 6:31. doi: 10.1038/s41421-020-0168-9

34. Wilk AJ, Rustagi A, Zhao NQ, Roque J, Martínez-Colón GJ, McKechnie JL, et al. A single-cell atlas of the peripheral immune response in patients with severe COVID-19. Nat Med (2020) 26(7):1070-6. doi: 10.1038/s41591-0200944-y

35. Fajgenbaum DC, June CH. Cytokine Storm. New Engl J Med (2020) 383 (23):2255-73. doi: 10.1056/NEJMra2026131

36. Liao M, Liu Y, Yuan J, Wen Y, Xu G, Zhao J, et al. Single-cell landscape of bronchoalveolar immune cells in patients with COVID-19. Nat Med (2020) 26(6):842-4. doi: 10.1038/s41591-020-0901-9

37. Zheng M, Gao Y, Wang G, Song G, Liu S, Sun D, et al. Functional exhaustion of antiviral lymphocytes in COVID-19 patients. Cell Mol Immunol (2020) 17 (5):533-5. doi: 10.1038/s41423-020-0402-2

38. Huang C, Wang Y, Li X, Ren L, Zhao J, Hu Y, et al. Clinical features of patients infected with 2019 novel coronavirus in Wuhan, China. Lancet (London England) (2020) 395(10223):497-506. doi: 10.1016/s0140-6736(20) 30183-5

39. Qin C, Zhou L, Hu Z, Zhang S, Yang S, Tao Y, et al. Dysregulation of Immune Response in Patients With Coronavirus 2019 (COVID-19) in Wuhan, China. Clin Infect Dis An Off Publ Infect Dis Soc America (2020) 71(15):762-8. doi: 10.1093/cid/ciaa248
40. Tan M, Liu Y, Zhou R, Deng X, Li F, Liang K, et al. Immunopathological characteristics of coronavirus disease 2019 cases in Guangzhou, China. Immunology (2020) 160(3):261-8. doi: 10.1111/imm.13223

41. Xu Z, Shi L, Wang Y, Zhang J, Huang L, Zhang C, et al. Pathological findings of COVID-19 associated with acute respiratory distress syndrome. Lancet Respiratory Med (2020) 8(4):420-2. doi: 10.1016/s2213-2600(20)30076-x

42. Diao B, Wang C, Tan Y, Chen X, Liu Y, Ning L, et al. Reduction and Functional Exhaustion of T Cells in Patients With Coronavirus Disease 2019 (COVID-19). Front Immunol (2020) 11:827:827. doi: 10.3389/ fimmu.2020.00827

43. Zheng HY, Zhang M, Yang CX, Zhang N, Wang XC, Yang XP, et al. Elevated exhaustion levels and reduced functional diversity of $\mathrm{T}$ cells in peripheral blood may predict severe progression in COVID-19 patients. Cell Mol Immunol (2020) 17(5):541-3. doi: 10.1038/s41423-020-0401-3

44. Zhang J, Xie B, Hashimoto K. Current status of potential therapeutic candidates for the COVID-19 crisis. Brain Behav Immun (2020) 87:59-73. doi: 10.1016/j.bbi.2020.04.046

45. Ye Q, Wang B, Mao J. The pathogenesis and treatment of the 'Cytokine Storm' in COVID-19. J Infect (2020) 80(6):607-13. doi: 10.1016/ j.jinf.2020.03.037

46. Robba C, Battaglini D, Pelosi P, Rocco PRM. Multiple organ dysfunction in SARS-CoV-2: MODS-CoV-2. Expert Rev Respiratory Med (2020) 14(9):8658. doi: $10.1080 / 17476348.2020 .1778470$

47. Klok FA, Kruip M, van der Meer NJM, Arbous MS, Gommers D, Kant KM, et al. Incidence of thrombotic complications in critically ill ICU patients with COVID-19. Thromb Res (2020) 191:145-7. doi: 10.1016/j.thromres. 2020.04.013

48. Joly BS, Siguret V, Veyradier A. Understanding pathophysiology of hemostasis disorders in critically ill patients with COVID-19. Intens Care Med (2020) 46(8):1603-6. doi: 10.1007/s00134-020-06088-1

49. Zuo Y, Estes SK, Ali RA, Gandhi AA, Yalavarthi S, Shi H, et al. Prothrombotic autoantibodies in serum from patients hospitalized with COVID-19. Sci Trans Med (2020) 12(570). doi: 10.1126/scitranslmed.abd3876

50. Abbas AK. Die and let live: eliminating dangerous lymphocytes. Cell (1996) 84(5):655-7. doi: 10.1016/s0092-8674(00)81042-9

51. Yu K, Wu Y, He J, Liu X, Wei B, Wen W, et al. Thymosin alpha-1 Protected T Cells from Excessive Activation in Severe COVID-19. (2020) 30(9):814-6. doi: 10.1038/s41422-020-0391-9

52. Tan W, Lu Y, Zhang J, Wang J, Dan Y, Tan Z, et al. Viral Kinetics and Antibody Responses in Patients with COVID-19. medRxiv (2020), 2020.03.24.20042382. doi: 10.1101/2020.03.24.20042382

53. Chakraborty S, Gonzalez J, Edwards K, Mallajosyula V, Buzzanco A, Sherwood R, et al. >Proinflammatory IgG Fc structures in patients with severe COVID-19. medRxiv (2020). doi: 10.1101/2020.05.15.20103341

54. Jaume M, Yip MS, Cheung CY, Leung HL, Li PH, Kien F, et al. Anti-severe acute respiratory syndrome coronavirus spike antibodies trigger infection of human immune cells via a $\mathrm{pH}$ - and cysteine protease-independent Fc $\gamma \mathrm{R}$ pathway. J Virol (2011) 85(20):10582-97. doi: 10.1128/jvi.00671-11

55. Liu L, Wei Q, Lin Q, Fang J, Wang H, Kwok H, et al. Anti-spike IgG causes severe acute lung injury by skewing macrophage responses during acute SARS-CoV infection. JCI Insight (2019) 4(4). doi: 10.1172/jci.insight.123158

56. Giamarellos-Bourboulis EJ, Netea MG, Rovina N, Akinosoglou K, Antoniadou A, Antonakos N, et al. Complex Immune Dysregulation in COVID-19 Patients with Severe Respiratory Failure. Cell Host Microbe (2020) 27(6):992-1000.e3. doi: 10.1016/j.chom.2020.04.009

57. Agrati C, Sacchi A, Bordoni V, Cimini E, Notari S, Grassi G, et al. Expansion of myeloid-derived suppressor cells in patients with severe coronavirus disease (COVID-19). Cell Death Different (2020) 27(11):3196-207. doi: 10.1038/s41418-020-0572-6

58. Choy EH, De Benedetti F, Takeuchi T, Hashizume M, John MR, Kishimoto T. Translating IL-6 biology into effective treatments. Nat Rev Rheumatol (2020) 16(6):335-45. doi: 10.1038/s41584-020-0419-z

59. Xu X, Han M, Li T, Sun W, Wang D, Fu B, et al. Effective treatment of severe COVID-19 patients with tocilizumab. Proc Natl Acad Sci U.S.A. (2020) 117 (20):10970-5. doi: 10.1073/pnas.2005615117

60. Luo P, Liu Y, Qiu L, Liu X, Liu D, Li J. Tocilizumab treatment in COVID-19: A single center experience. J Med Virol (2020) 92(7):814-8. doi: 10.1002/ jmv.25801 
61. Gritti G, Raimondi F, Ripamonti D, Riva I, Landi F, Alborghetti L, et al. Use of siltuximab in patients with COVID-19 pneumonia requiring ventilatory support. medRxiv (2020), 2020.04.01.20048561. doi: 10.1101/ 2020.04.01.20048561

62. Roumier M, Paule R, Groh M, Vallée A, Ackermann F. Interleukin-6 blockade for severe COVID-19. medRxiv (2020), 2020.04.20.20061861. doi: 10.1101/2020.04.20.20061861

63. Somers EC, Eschenauer GA, Troost JP, Golob JL, Gandhi TN, Wang L, et al. Tocilizumab for treatment of mechanically ventilated patients with COVID19. Clin Infect Dis An Off Publ Infect Dis Soc America (2020). doi: 10.1093/ $\mathrm{cid} / \mathrm{ciaa} 954$

64. Potere N, Di Nisio M, Cibelli D, Scurti R, Frattari A, Porreca E, et al. Interleukin-6 receptor blockade with subcutaneous tocilizumab in severe COVID-19 pneumonia and hyperinflammation: a case-control study. Ann Rheumatic Dis (2020). doi: 10.1136/annrheumdis-2020-218243

65. Radbel J, Narayanan N, Bhatt PJ. Use of Tocilizumab for COVID-19Induced Cytokine Release Syndrome: A Cautionary Case Report. Chest (2020) 158(1):e15-e9. doi: 10.1016/j.chest.2020.04.024

66. Duan K, Liu B, Li C, Zhang H, Yu T, Qu J, et al. Effectiveness of convalescent plasma therapy in severe COVID-19 patients. Proc Natl Acad Sci U.S.A. (2020) 117(17):9490-6. doi: 10.1073/pnas.2004168117

67. Shen C, Wang Z, Zhao F, Yang Y, Li J, Yuan J, et al. Treatment of 5 Critically Ill Patients With COVID-19 With Convalescent Plasma. Jama (2020) 323 (16):1582-9. doi: 10.1001/jama.2020.4783

68. Zhang B, Liu S, Tan T, Huang W, Dong Y, Chen L, et al. Treatment With Convalescent Plasma for Critically Ill Patients With Severe Acute Respiratory Syndrome Coronavirus 2 Infection. Chest (2020) 158(1):e9e13. doi: $10.1016 /$ j.chest.2020.03.039

69. Zeng QL, Yu ZJ, Gou JJ, Li GM, Ma SH, Zhang GF, et al. Effect of Convalescent Plasma Therapy on Viral Shedding and Survival in Patients With Coronavirus Disease 2019. J Infect Dis (2020) 222(1):38-43. doi: 10.1093/infdis/jiaa228

70. Salazar E, Perez KK, Ashraf M, Chen J, Castillo B, Christensen PA, et al. Treatment of Coronavirus Disease 2019 (COVID-19) Patients with Convalescent Plasma. Am J Pathol (2020) 190(8):1680-90. doi: 10.1016/ j.ajpath.2020.05.014

71. Li L, Zhang W, Hu Y, Tong X, Zheng S, Yang J, et al. Effect of Convalescent Plasma Therapy on Time to Clinical Improvement in Patients With Severe and Life-threatening COVID-19: A Randomized Clinical Trial. Jama (2020) 324(5):460-70. doi: 10.1001/jama.2020.10044

72. Xia X, Li K, Wu L, Wang Z, Zhu M, Huang B, et al. Improved clinical symptoms and mortality among patients with severe or critical COVID-19 after convalescent plasma transfusion. Blood (2020) 136(6):755-9. doi: 10.1182/blood.2020007079

73. Cao W, Liu X, Bai T, Fan H, Hong K, Song H, et al. High-Dose Intravenous Immunoglobulin as a Therapeutic Option for Deteriorating Patients With Coronavirus Disease 2019. Open Forum Infect Dis (2020) 7(3):ofaa102. doi: 10.1093/ofid/ofaa102

74. Xie Y, Cao S, Dong H, Li Q, Chen E, Zhang W, et al. Effect of regular intravenous immunoglobulin therapy on prognosis of severe pneumonia in patients with COVID-19. J Infect (2020) 81(2):318-56. doi: 10.1016/ j.jinf.2020.03.044

75. Liu Y, Pan Y, Hu Z, Wu M, Wang C, Feng Z, et al. Thymosin Alpha 1 Reduces the Mortality of Severe Coronavirus Disease 2019 by Restoration of Lymphocytopenia and Reversion of Exhausted T Cells. Clin Infect Dis An Off Publ Infect Dis Soc America (2020) 71(16):2150-7. doi: 10.1093/cid/ ciaa630

76. Ling Y, Xu SB, Lin YX, Tian D, Zhu ZQ, Dai FH, et al. Persistence and clearance of viral RNA in 2019 novel coronavirus disease rehabilitation patients. Chin Med J (Engl) (2020) 133(9):1039-43. doi: 10.1097/ $\mathrm{cm} 9.0000000000000774$

77. Zha L, Li S, Pan L, Tefsen B, Li Y, French N, et al. Corticosteroid treatment of patients with coronavirus disease 2019 (COVID-19). Med J Aust (2020) 212 (9):416-20. doi: 10.5694/mja2.50577

78. Wang D, Wang J, Jiang Q, Yang J, Li J, Gao C, et al. No Clear Benefit to the Use of Corticosteroid as Treatment in Adult Patients with Coronavirus Disease 2019 : A Retrospective Cohort Study. medRxiv (2020), 2020.04.21.20066258. doi: 10.1101/2020.04.21.20066258
79. Wu C, Chen X, Cai Y, Xia J, Zhou X, Xu S, et al. Risk Factors Associated With Acute Respiratory Distress Syndrome and Death in Patients With Coronavirus Disease 2019 Pneumonia in Wuhan, China. JAMA Intern Med (2020) 180(7):934-43. doi: 10.1001/jamainternmed.2020.0994

80. Yang SS, Lipes J. Corticosteroids for critically ill COVID-19 patients with cytokine release syndrome: a limited case series. Can J Anaesthesia J Canadien D'anesthesie (2020) 67(10):1462-4. doi: 10.1007/s12630-02001700-w

81. Wang Y, Jiang W, He Q, Wang C, Liu B, Zhou P, et al. Early, low-dose and short-term application of corticosteroid treatment in patients with severe COVID-19 pneumonia: single-center experience from Wuhan, China. medRxiv (2020), 2020.03.06.20032342. doi: 10.1101/2020.03.06.20032342

82. Liu K, Fang YY, Deng Y, Liu W, Wang MF, Ma JP, et al. Clinical characteristics of novel coronavirus cases in tertiary hospitals in Hubei Province. Chin Med J (Engl) (2020) 133(9):1025-31. doi: 10.1097/ $\mathrm{cm} 9.0000000000000744$

83. Hung IF, Lung KC, Tso EY, Liu R, Chung TW, Chu MY, et al. Triple combination of interferon beta-1b, lopinavir-ritonavir, and ribavirin in the treatment of patients admitted to hospital with COVID-19: an open-label, randomised, phase 2 trial. Lancet (London England) (2020) 395 (10238):1695-704. doi: 10.1016/s0140-6736(20)31042-4

84. Wang N, Zhan Y, Zhu L, Hou Z, Liu F, Song P, et al. Retrospective Multicenter Cohort Study Shows Early Interferon Therapy Is Associated with Favorable Clinical Responses in COVID-19 Patients. Cell Host Microbe (2020) 28(3):455-64.e2. doi: 10.1016/j.chom.2020.07.005

85. Velazquez-Salinas L, Verdugo-Rodriguez A, Rodriguez LL, Borca MV. The Role of Interleukin 6 During Viral Infections. Front Microbiol (2019) 10:1057:1057. doi: 10.3389/fmicb.2019.01057

86. Mihara M, Hashizume M, Yoshida H, Suzuki M, Shiina M. IL-6/IL-6 receptor system and its role in physiological and pathological conditions. Clin Sci (London Engl 1979) (2012) 122(4):143-59. doi: 10.1042/cs20110340

87. Schett G, Sticherling M, Neurath MF. COVID-19: risk for cytokine targeting in chronic inflammatory diseases? Nat Rev Immunol (2020) 20(5):271-2. doi: $10.1038 / \mathrm{s} 41577-020-0312-7$

88. Marano G, Vaglio S, Pupella S, Facco G, Catalano L, Liumbruno GM, et al. Convalescent plasma: new evidence for an old therapeutic tool? Blood Transfus (2016) 14(2):152-7. doi: 10.2450/2015.0131-15

89. Arabi Y, Balkhy H, Hajeer AH, Bouchama A, Hayden FG, Al-Omari A, et al. Feasibility, safety, clinical, and laboratory effects of convalescent plasma therapy for patients with Middle East respiratory syndrome coronavirus infection: a study protocol. SpringerPlus (2015) 4:709. doi: 10.1186/s40064015-1490-9

90. Cheng Y, Wong R, Soo YO, Wong WS, Lee CK, Ng MH, et al. Use of convalescent plasma therapy in SARS patients in Hong Kong. Eur J Clin Microbiol Infect Dis Off Publ Eur Soc Clin Microbiol (2005) 24(1):44-6. doi: 10.1007/s10096-004-1271-9

91. Hung IF, To KK, Lee CK, Lee KL, Chan K, Yan WW, et al. Convalescent plasma treatment reduced mortality in patients with severe pandemic influenza A (H1N1) 2009 virus infection. Clin Infect Dis An Off Publ Infect Dis Soc America (2011) 52(4):447-56. doi: 10.1093/cid/ciq106

92. Rojas M, Rodríguez Y, Monsalve DM, Acosta-Ampudia Y, Camacho B, Gallo JE, et al. Convalescent plasma in Covid-19: Possible mechanisms of action. Autoimmun Rev (2020) 19(7):102554-. doi: 10.1016/j.autrev.2020.102554

93. Abe Y, Horiuchi A, Miyake M, Kimura S. Anti-cytokine nature of natural human immunoglobulin: one possible mechanism of the clinical effect of intravenous immunoglobulin therapy. Immunol Rev (1994) 139:5-19. doi: 10.1111/j.1600-065x.1994.tb00854.x

94. Sahu KK, Jindal V, Siddiqui AD, Cerny J, Gerber JM. Convalescent plasma therapy: A passive therapy for an aggressive COVID-19. J Med Virol (2020) 92(11):2251-3. doi: 10.1002/jmv.26047

95. Garraud O, Heshmati F, Pozzetto B, Lefrere F, Girot R, Saillol A, et al. Plasma therapy against infectious pathogens, as of yesterday, today and tomorrow. Transfus Clin Biol (2016) 23(1):39-44. doi: 10.1016/ j.tracli.2015.12.003

96. Perez EE, Orange JS, Bonilla F, Chinen J, Chinn IK, Dorsey M, et al. Update on the use of immunoglobulin in human disease: A review of evidence. J Allergy Clin Immunol (2017) 139(3s):S1-s46. doi: 10.1016/j.jaci.2016. 09.023 
97. Arabi YM, Arifi AA, Balkhy HH, Najm H, Aldawood AS, Ghabashi A, et al. Clinical course and outcomes of critically ill patients with Middle East respiratory syndrome coronavirus infection. Ann Intern Med (2014) 160 (6):389-97. doi: 10.7326/m13-2486

98. Hung IFN, To KKW, Lee CK, Lee KL, Yan WW, Chan K, et al. Hyperimmune IV immunoglobulin treatment: a multicenter double-blind randomized controlled trial for patients with severe 2009 influenza A (H1N1) infection. Chest (2013) 144(2):464-73. doi: 10.1378/chest.12-2907

99. Wang JT, Sheng WH, Fang CT, Chen YC, Wang JL, Yu CJ, et al. Clinical manifestations, laboratory findings, and treatment outcomes of SARS patients. Emerg Infect Dis (2004) 10(5):818-24. doi: 10.3201/eid1005.030640

100. Maddur MS, Rabin M, Hegde P, Bolgert F, Guy M, Vallat JM, et al. Intravenous immunoglobulin exerts reciprocal regulation of Th1/Th17 cells and regulatory $\mathrm{T}$ cells in Guillain-Barré syndrome patients. Immunol Res (2014) 60(2-3):320-9. doi: 10.1007/s12026-014-8580-6

101. Schwab I, Nimmerjahn F. Intravenous immunoglobulin therapy: how does IgG modulate the immune system? Nat Rev Immunol (2013) 13(3):176-89. doi: $10.1038 /$ nri3401

102. Charlet R, Sendid B, Kaveri SV, Poulain D, Bayry J, Jawhara S. Intravenous Immunoglobulin Therapy Eliminates Candida albicans and Maintains Intestinal Homeostasis in a Murine Model of Dextran Sulfate SodiumInduced Colitis. Int J Mol Sci (2019) 20(6). doi: 10.3390/ijms20061473

103. Smith SV, Liles DK, White GC, Brecher ME. Successful treatment of transient acquired factor $\mathrm{X}$ deficiency by plasmapheresis with concomitant intravenous immunoglobulin and steroid therapy. Am J Hematol (1998) 57(3):245-52. doi: 10.1002/(sici)1096-8652(199803)57:3<245::aid-ajh13>3.0.co;2-9

104. Costantini C, Bellet MM, Pariano M, Renga G, Stincardini C, Goldstein AL, et al. A Reappraisal of Thymosin Alphal in Cancer Therapy. Front Oncol (2019) 9:873:873. doi: 10.3389/fonc.2019.00873

105. Low TL, Goldstein AL. Thymosins: structure, function and therapeutic applications. Thymus (1984) 6(1-2):27-42.

106. Sherman KE. Thymosin alpha 1 for treatment of hepatitis $C$ virus: promise and proof. Ann New Y Acad Sci (2010) 1194:136-40. doi: 10.1111/j.17496632.2010.05460.x

107. Liu F, Wang HM, Wang T, Zhang YM, Zhu X. The efficacy of thymosin $\alpha 1$ as immunomodulatory treatment for sepsis: a systematic review of randomized controlled trials. BMC Infect Dis (2016) 16:488. doi: 10.1186/s12879-016-1823-5

108. Zatz MM, Oliver J, Samuels C, Skotnicki AB, Sztein MB, Goldstein AL. Thymosin increases production of T-cell growth factor by normal human peripheral blood lymphocytes. Proc Natl Acad Sci U.S.A. (1984) 81(9):28825. doi: 10.1073/pnas.81.9.2882

109. Heming N, Sivanandamoorthy S, Meng P, Bounab R, Annane D. Immune Effects of Corticosteroids in Sepsis. Front Immunol (2018) 9:1736:1736. doi: 10.3389/fimmu.2018.01736

110. Thompson BT. Glucocorticoids and acute lung injury. Crit Care Med (2003) 31(4 Suppl):S253-7. doi: 10.1097/01.Ccm.0000057900.19201.55

111. Ye Z, Wang Y, Colunga-Lozano LE, Prasad M, Tangamornsuksan W, Rochwerg B, et al. Efficacy and safety of corticosteroids in COVID-19 based on evidence for COVID-19, other coronavirus infections, influenza, community-acquired pneumonia and acute respiratory distress syndrome: a systematic review and meta-analysis. CMAJ (2020) 192(27):E756-e67. doi: 10.1503/cmaj.200645

112. Xu K, Chen Y, Yuan J, Yi P, Ding C, Wu W, et al. Factors Associated With Prolonged Viral RNA Shedding in Patients with Coronavirus Disease 2019 (COVID-19). Clin Infect Dis An Off Publ Infect Dis Soc America (2020) 71 (15):799-806. doi: 10.1093/cid/ciaa351

113. Yan D, Liu XY, Zhu YN, Huang L, Dan BT, Zhang GJ, et al. Factors associated with prolonged viral shedding and impact of lopinavir/ ritonavir treatment in hospitalised non-critically ill patients with SARSCoV-2 infection. Eur Respir J (2020) 56(1). doi: 10.1183/13993003.007992020

114. Li X, Xu S, Yu M, Wang K, Tao Y, Zhou Y, et al. Risk factors for severity and mortality in adult COVID-19 inpatients in Wuhan. J Allergy Clin Immunol (2020) 146(1):110-8. doi: 10.1016/j.jaci.2020.04.006

115. Horby P, Lim WS, Emberson JR, Mafham M, Bell JL, Linsell L, et al. Dexamethasone in Hospitalized Patients with Covid-19 - Preliminary Report. N Engl J Med (2020). doi: 10.1056/NEJMoa2021436
116. Tang J. What can we learn about corticosteroid therapy as a treatment for COVID-19? Osteoporosis Int J Established As Result Coop Between Eur Foundation Osteoporosis Natl Osteoporosis Foundation USA (2020) 31 (8):1595. doi: 10.1007/s00198-020-05487-w

117. Goel RR, Wang X, O'Neil LJ, Nakabo S, Hasneen K, Gupta S, et al. Interferon lambda promotes immune dysregulation and tissue inflammation in TLR7induced lupus. Proc Natl Acad Sci U.S.A. (2020) 117(10):5409-19. doi: $10.1073 /$ pnas. 1916897117

118. Samuel CE. Antiviral actions of interferons. Clin Microbiol Rev (2001) 14 (4):778-809. doi: 10.1128/cmr.14.4.778-809.2001

119. Chan JF, Yao Y, Yeung ML, Deng W, Bao L, Jia L, et al. Treatment With Lopinavir/Ritonavir or Interferon- $\beta 1 \mathrm{~b}$ Improves Outcome of MERS-CoV Infection in a Nonhuman Primate Model of Common Marmoset. J Infect Dis (2015) 212(12):1904-13. doi: 10.1093/infdis/jiv392

120. Haagmans BL, Kuiken T, Martina BE, Fouchier RA, Rimmelzwaan GF, van Amerongen $\mathrm{G}$, et al. Pegylated interferon-alpha protects type 1 pneumocytes against SARS coronavirus infection in macaques. Nat Med (2004) 10(3):2903. doi: $10.1038 / \mathrm{nm} 1001$

121. Loutfy MR, Blatt LM, Siminovitch KA, Ward S, Wolff B, Lho H, et al. Interferon alfacon-1 plus corticosteroids in severe acute respiratory syndrome: a preliminary study. Jama (2003) 290(24):3222-8. doi: 10.1001/ jama.290.24.3222

122. Omrani AS, Saad MM, Baig K, Bahloul A, Abdul-Matin M, Alaidaroos AY, et al. Ribavirin and interferon alfa-2a for severe Middle East respiratory syndrome coronavirus infection: a retrospective cohort study. Lancet Infect Dis (2014) 14(11):1090-5. doi: 10.1016/s1473-3099(14)70920-x

123. Schneider LC, Baz Z, Zarcone C, Zurakowski D. Long-term therapy with recombinant interferon-gamma (rIFN-gamma) for atopic dermatitis. Ann Allergy Asthma Immunol Off Publ Am Coll Allergy Asthma Immunol (1998) 80(3):263-8. doi: 10.1016/s1081-1206(10)62968-7

124. Dijkmans R, Billiau A. Interferon gamma: a master key in the immune system. Curr Opin Immunol (1988) 1(2):269-74. doi: 10.1016/0952-7915(88) 90013-1

125. Nagata N, Iwata N, Hasegawa H, Fukushi S, Harashima A, Sato Y, et al. Mouse-passaged severe acute respiratory syndrome-associated coronavirus leads to lethal pulmonary edema and diffuse alveolar damage in adult but not young mice. Am J Pathol (2008) 172(6):1625-37. doi: 10.2353/ ajpath.2008.071060

126. Scagnolari C, Vicenzi E, Bellomi F, Stillitano MG, Pinna D, Poli G, et al. Increased sensitivity of SARS-coronavirus to a combination of human type I and type II interferons. Antiviral Ther (2004) 9(6):1003-11.

127. de Lang $\mathrm{A}$, Osterhaus $\mathrm{AD}$, Haagmans $\mathrm{BL}$. Interferon-gamma and interleukin-4 downregulate expression of the SARS coronavirus receptor ACE2 in Vero E6 cells. Virology (2006) 353(2):474-81. doi: 10.1016/ j.virol.2006.06.011

128. Dinnon KH, Leist SR, Schäfer A, Edwards CE, Martinez DR, Montgomery $\mathrm{SA}$, et al. A mouse-adapted SARS-CoV-2 model for the evaluation of COVID-19 medical countermeasures. bioRxiv (2020), 2020.05.06.081497. doi: 10.1101/2020.05.06.081497

129. Broggi A, Ghosh S, Sposito B, Spreafico R, Balzarini F, Lo Cascio A, et al. Type III interferons disrupt the lung epithelial barrier upon viral recognition. Sci (N Y NY) (2020) 369(6504):706-12. doi: 10.1126/science. abc3545

130. Major J, Crotta S, Llorian M, McCabe TM, Gad HH, Priestnall SL, et al. and III interferons disrupt lung epithelial repair during recovery from viral infection. Sci (N Y NY) (2020) 369(6504):712-7. doi: 10.1126/ science.abc2061

131. Rabaan AA, Al-Ahmed SH, Sah R, Al-Tawfiq JA, Al-Qaaneh AM, Al-Jamea $\mathrm{LH}$, et al. Recent advances in vaccine and immunotherapy for COVID-19. Hum Vaccines Immunotherapeut (2020) 16(12):3011-22. doi: 10.1080/ 21645515.2020.1825896

132. Jackson LA, Anderson EJ, Rouphael NG, Roberts PC, Makhene M, Coler RN, et al. An mRNA Vaccine against SARS-CoV-2 - Preliminary Report. New Engl J Med (2020) 383(20):1920-31. doi: 10.1056/NEJMoa2022483

133. Zhu FC, Guan XH, Li YH, Huang JY, Jiang T, Hou LH, et al. Immunogenicity and safety of a recombinant adenovirus type-5-vectored COVID-19 vaccine in healthy adults aged 18 years or older: a randomised, 
double-blind, placebo-controlled, phase 2 trial. Lancet (London England) (2020) 396(10249):479-88. doi: 10.1016/s0140-6736(20)31605-6

134. Folegatti PM, Ewer KJ, Aley PK, Angus B, Becker S, Belij-Rammerstorfer S, et al. Safety and immunogenicity of the ChAdOx $1 \mathrm{nCoV}-19$ vaccine against SARS-CoV-2: a preliminary report of a phase $1 / 2$, single-blind, randomised controlled trial. Lancet (London England) (2020) 396(10249):467-78. doi: 10.1016/s0140-6736(20)31604-4

135. Keech C, Albert G, Cho I, Robertson A, Reed P, Neal S, et al. Phase 1-2 Trial of a SARS-CoV-2 Recombinant Spike Protein Nanoparticle Vaccine. New Engl J Med (2020) 383(24):2320-32. doi: 10.1056/NEJMoa2026920
Conflict of Interest: The authors declare that the research was conducted in the absence of any commercial or financial relationships that could be construed as a potential conflict of interest.

Copyright $\odot 2021$ Xie, Zhang, Li, Yuan and Shang. This is an open-access article distributed under the terms of the Creative Commons Attribution License (CC BY). The use, distribution or reproduction in other forums is permitted, provided the original author(s) and the copyright owner(s) are credited and that the original publication in this journal is cited, in accordance with accepted academic practice. No use, distribution or reproduction is permitted which does not comply with these terms. 